\title{
ENERGY EXPENDITURE IN YOGA VERSUS OTHER FORMS OF PHYSICAL ACTIVITY
}

\author{
by
}

Sally A. Sherman

\author{
B.A., Slippery Rock University of Pennsylvania \\ M.Ed., Pennsylvania State University \\ M.S., University of Pittsburgh
}

\author{
Submitted to the Graduate Faculty of \\ the School of Education in partial fulfillment \\ of the requirements for the degree of Doctor of Philosophy
}

University of Pittsburgh 


\title{
UNIVERSITY OF PITTSBURGH \\ SCHOOL OF EDUCATION
}

This dissertation was presented

by

\author{
Sally A. Sherman
}

It was defended on

April 22, 2016

and approved by

Kelliann K. Davis, Ph.D., Assistant Professor, Health and Physical Activity

Ryan L. Minster, Ph.D., M.S.I.S., Assistant Professor, Human Genetics

Renee J. Rogers, Ph.D., Assistant Professor, Health and Physical Activity

Dissertation Advisor: John M. Jakicic Ph.D., Professor, Health and Physical Activity 
Copyright (C) by Sally A. Sherman

2016 


\title{
ENERGY EXPENDITURE IN YOGA VERSUS OTHER FORMS OF PHYSICAL
}

\author{
ACTIVITY \\ Sally A. Sherman, Ph.D. \\ University of Pittsburgh, 2016
}

Vinyasa yoga involves moving continuously through poses versus holding poses which is present in other forms of yoga. However, the energy cost of Vinyasa yoga has not been well-established.

PURPOSE: This study compared energy expenditure (EE) and heart rate (HR) during acute bouts of Vinyasa yoga and two treadmill walking protocols.

METHODS: Complete data were available for analysis on 28 participants (15 males, 13 females) who performed 60-minute bouts of yoga (YOGA) and treadmill walking, with EE assessed via indirect calorimetry. Treadmill walking consisted of two sessions: 1) participants walked at their self-selected brisk pace (SELF), 2) participants walked at pace that matched their HR to that of their yoga session (HR-Match).

RESULTS: EE was significantly lower in YOGA compared to both the HR-Match (difference=82.2 $\pm 42.1 \mathrm{kcal} ; \mathrm{p}<0.001$ ) and SELF (difference $=44.1 \pm 70.0 \mathrm{kcal} ; \mathrm{p}=0.003$ ), and in SELF compared to HR-Match (difference=38.1 $\pm 75.3 \mathrm{kcal}$; $\mathrm{p}=0.012$ ). HR was lower in SELF compared to HR-Match (difference $=9.9 \pm 13.7 \mathrm{bpm}$; $\mathrm{p}=0.001$ ) and YOGA (difference $=9.2 \pm 14.6$ bpm; $\mathrm{p}=0.003$ ), with no difference between HR-Match and YOGA (0.8 $\pm 2.9 \mathrm{bpm} ; \mathrm{p}=0.166)$. RPE was lower in SELF compared to YOGA (difference=2.0 \pm 1.6 ; $\mathrm{p}<0.001$ ) and HR-Match compared 
to YOGA (difference=1.0 \pm 1.6 ; $\mathrm{p}=0.002$ ), but no difference in RPE between HR-Match and SELF (difference=1.0 $\pm 2.1 ; \mathrm{p}=0.022$ ). Analyses were repeated using only the initial 45 minutes from each of the sessions. Results showed EE was significantly lower in YOGA compared to HR-Match (difference=72.0 $\pm 37.5 \mathrm{kcal} ; \quad \mathrm{p}<0.001)$ but not compared to SELF (difference=8.8 $\pm 53.9 \mathrm{kcal}$; $\mathrm{p}=0.393$ ); however, EE was lower in SELF compared to HR-Match (difference $=63.2 \pm 60.8 \mathrm{kcal} ; \mathrm{p}<0.001$ ). HR data revealed a significantly lower HR in SELF compared to HR Match (difference=16.6 \pm 13.9 bpm; $<<0.001$ ) and YOGA (difference=16.3 \pm 14.6 bpm; $\mathrm{p}<0.001$ ), but no significant difference in the HR between YOGA and HR-Match (difference=0.2 $\pm 3.7 \mathrm{bpm} ; \mathrm{p}=0.796$ ). Gender did not significantly influence the pattern of the results observed.

CONCLUSIONS: Across a 60-minute period, EE in YOGA is significantly lower than both SELF and HR-Match. When the restorative component of YOGA was removed from the analysis, EE in YOGA was comparable to SELF. Thus, the non-restorative component of YOGA may be a viable alternative to SELF physical activity to achieve physical activity public health guidelines. 
TABLE OF CONTENTS

1.0

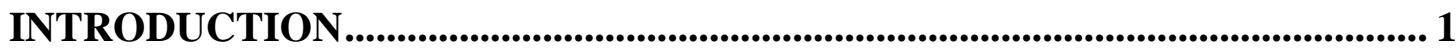

1.1 YOGA: AN ALTERNATIVE FORM OF PHYSICAL ACTIVITY FOR

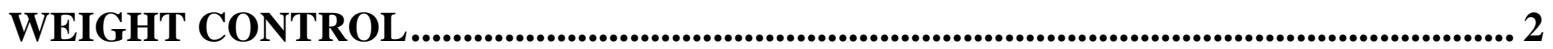

1.2 SPECIFIC AIMS AND HYPOTHESES …........................................................... 5

1.3 CLINICAL SIGNIFICANCE .............................................................................. 6

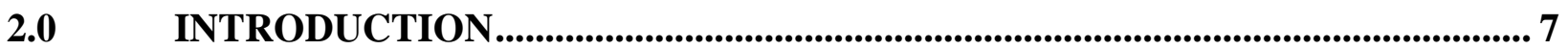

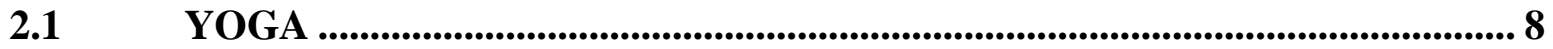

2.1.1 Stress, Depression, Anxiety, Mood............................................................... 9

2.1.2 Pain ..................................................................................................................... 11

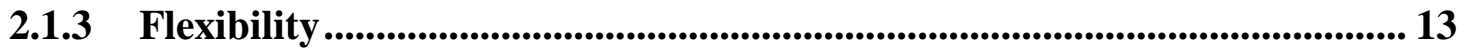

2.1.4 Sleep .......................................................................................................................... 14

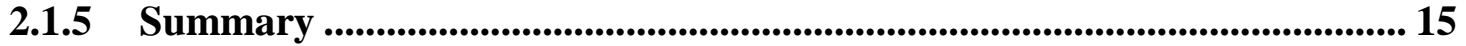

2.2 BODY WEIGHT REGULATION AND OBESITY ........................................ 16

2.2.1 Energy Expenditure and Obesity .................................................................... 17

2.2.2 Stress Management and Obesity …..................................................................... 19

2.2.3 Mood \& Depressive Symptoms and Obesity ...................................................... 20

2.2.4 Pain and Obesity ............................................................................................... 22

2.2.5 Sleep and Obesity................................................................................................ 23 


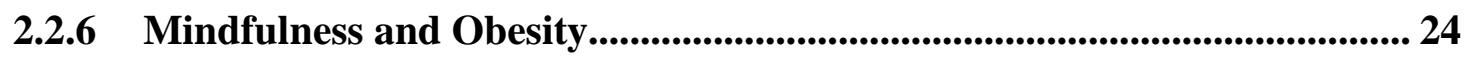

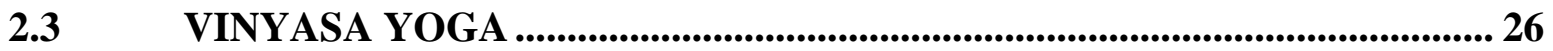

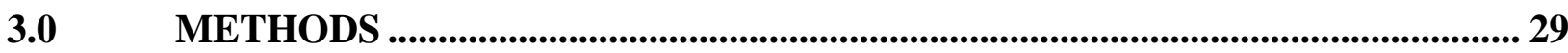

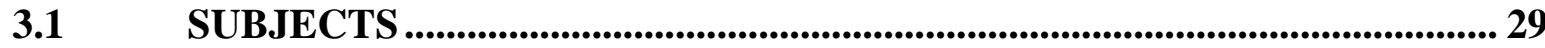

RECRUITMENT AND SCREENING PROCEDURES ............................. 30

ORIENTATION AND FAMILIARIZATION SESSION ........................... 31

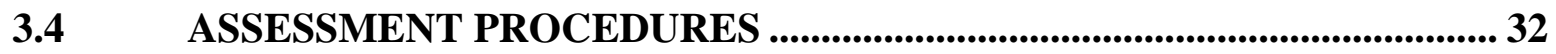

EXPERIMENTAL DESIGN .................................................................. 34

EXPERIMENTAL CONDITIONS ......................................................... 35

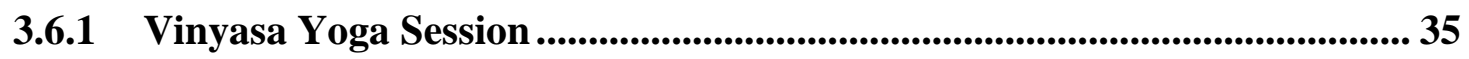

3.6.2 Heart Rate Matched Walking Session ....................................................... 36

3.6.3 Self-Selected Intensity Walking Session ............................................ 37

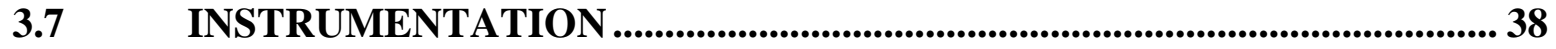

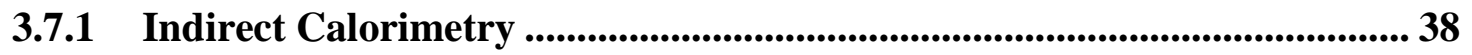

3.7.2 Heart Rate Monitoring..................................................................... 38

STATISTICAL ANALYSIS ........................................................................... 39

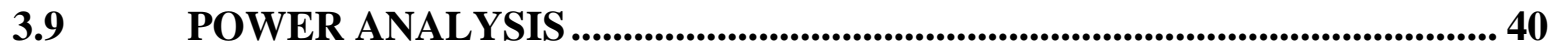

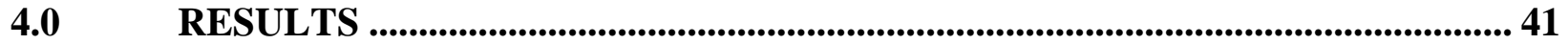

PARTICIPANTS $\ldots .1 \quad$ PA..................................................................................... 41

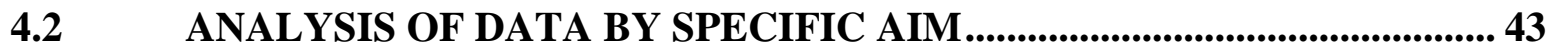

4.2.1 Specific Aim 1: Energy expenditure across exercise conditions................. 43

4.2.2 Specific Aim 2: Heart rate across exercise conditions................................ 50 
4.2.3 Specific Aim 3: Ratings of perceived exertion (RPE) across exercise

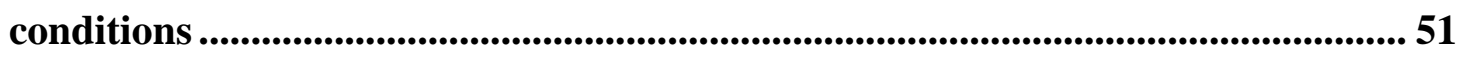

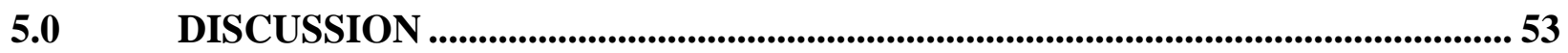

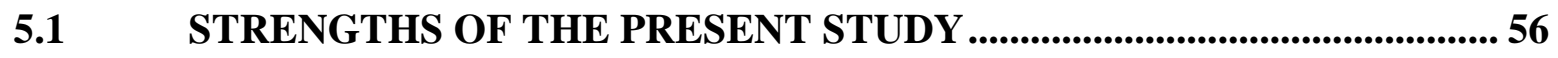

5.2 LIMITATIONS AND RECOMMENDATIONS FOR FUTURE

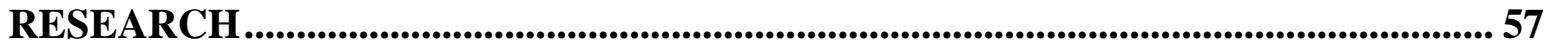

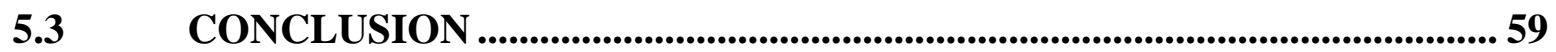

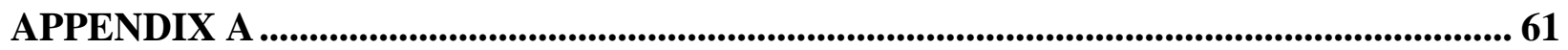

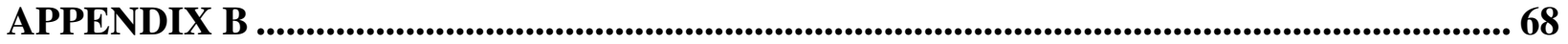

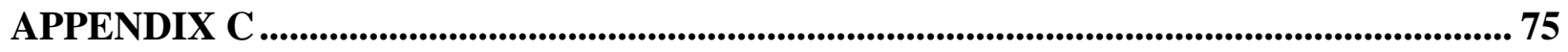

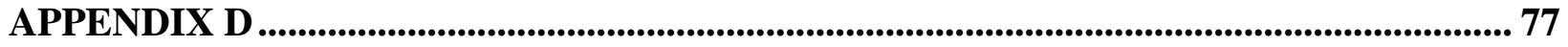

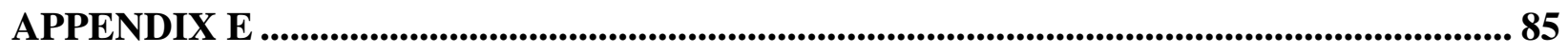

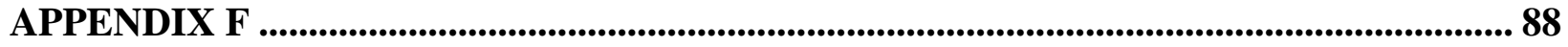

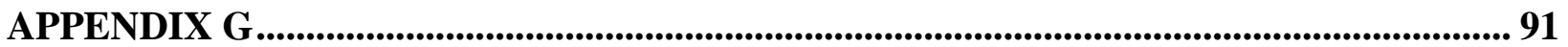

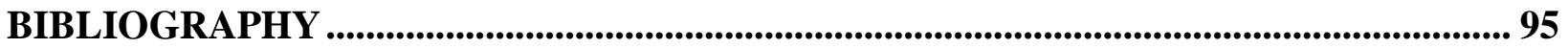




\section{LIST OF TABLES}

Table 1. Participant Descriptive Variables ...................................................................................... 43

Table 2. Experimental Session (1-60 minutes) with Post-Hoc Analysis ( $\mathrm{N}=28)$........................... 46

Table 3. Comparison of heart rate, energy expenditure, metabolic equivalents, and respiratory exchange ratio between females and males across the experimental conditions during minutes 1-

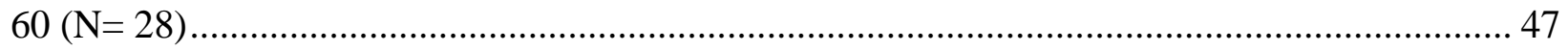

Table 4. Experimental Session (minutes 1-45) with Post-Hoc Analysis ( $\mathrm{N}=28)$.......................... 48

Table 5. Comparison of heart rate, energy expenditure, metabolic equivalents, and respiratory exchange ratio between females and males across the experimental conditions during minutes 1$45(\mathrm{~N}=28)$ 49 


\section{LIST OF FIGURES}

Figure 1. Pathways by which Yoga may be Associated with Reduced Body Weight.............17

Figure 2. Participant Recruitment and Enrollment....................................42

Figure 3. Energy Expenditure (kcal/min) across the Exercise Sessions.......................50

Figure 4. Heart Rate (beats/minute) across the Exercise Sessions.........................51

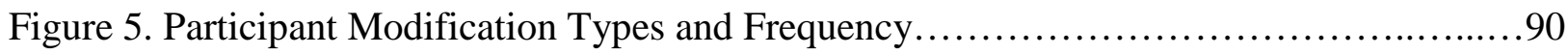

Figure 6. Flow Chart for Heart Rate Matched Walking Session............................94 


\subsection{INTRODUCTION}

Physical inactivity is a serious public health concern within the United States. Estimates from objectively measured physical activity indicate that only approximately $5 \%$ of adults in the United States engage in recommended levels to positively impact health. ${ }^{1}$ This is of significant concern because low levels of physical activity have been associated with increased mortality, with estimates of approximately 250,000 premature deaths annually attributed to insufficient physical activity. ${ }^{2}$ Moreover, low physical activity is associated with increased risk of numerous health conditions such as cardiovascular disease, diabetes, cancer, musculoskeletal limitations, and others. $^{2}$ Thus, low physical activity and its associated health conditions contribute significantly to increased health care expenditure. ${ }^{3}$

Weight gain that results in excess body fatness and overweight or obesity is a prevalent health condition in the United States, ${ }^{4}$ which is associated with numerous chronic health conditions. ${ }^{5,6}$ Weight gain and the resulting overweight or obesity are due to an imbalance between energy intake and energy expenditure, in which energy intake exceeds energy expenditure. Thus, low levels of physical activity contribute to this energy imbalance, and therefore, have been implicated as a contributing behavior to weight gain and onset of obesity. Thus, physical activity has been recommended as an important lifestyle behavior to both prevent weight gain and to effectively treat overweight and obesity. ${ }^{7}$ 
The majority of research on the role of physical activity in the prevention and treatment of obesity has focused on either aerobic (e.g., walking) or resistance (e.g., strength training) forms of activity. ${ }^{7}$ Based on this evidence, there is wide support for inclusion of aerobic forms of physical activity to prevent weight gain, induce modest weight loss, and assist in prevention of weight regain following weight loss. ${ }^{7}$ While also recommended as an important form of physical activity based on its impact on numerous health-related outcomes, there are fewer studies that have examined resistance training as a strategy to prevent weight gain and to induce weight loss. ${ }^{2,7}$ Moreover, based on the available evidence, resistance training appears to have significant but modest effects on weight loss. ${ }^{2,7}$ Thus, clinical treatment recommendations for obesity have typically encouraged inclusion of aerobic and/or resistance forms of physical activity. However, little is known about other forms of physical activity that may be effective for preventing weight gain or eliciting weight loss, which is a research gap that warrants investigation.

\subsection{YOGA: AN ALTERNATIVE FORM OF PHYSICAL ACTIVITY FOR WEIGHT CONTROL}

Yoga is a broad term used to describe mental, physical, and spiritual disciplines which originated in ancient India. Rooted in Hindu philosophy, the word Yoga means "yoke," "to join," or "to unite". ${ }^{8}$ It is now translated into different styles and interpretations from what the ancient practice was at its inception. While Yoga has deep-rooted philosophical pieces including meditation and chanting, it is the asanas (or poses) that have evolved in the Western culture as a form of physical activity. Due to the gentleness of the asanas and how they are performed in one 
spot on the floor without costly equipment, yoga has been made popular among many different ages, movement abilities and special needs. ${ }^{9}$

Often seen as a healing, alternative medicine, yoga is supported by evidence to decrease stress, ${ }^{10,11}$ mitigate pain, ${ }^{12-14}$ enhance mood and diminish depression, ${ }^{15,16}$ increase flexibility, ${ }^{17,18}$ and to enhance sleep. ${ }^{19,20}$ In addition, yoga has been shown to reduce resting blood pressure and heart rate ${ }^{21}$ and to potentially impact negative age-related cardiovascular effects. ${ }^{22}$ However, yoga has not been extensively studied to determine its potential impact as a form of physical activity to prevent and treat obesity.

Key to yoga being considered a form of physical activity that may be effective for weight control is its ability to significantly contribute to an increase in energy expenditure. However, there has been limited research conducted to examine the energy cost of yoga. In one of the few studies that has been conducted, Hagins, et al. ${ }^{22}$ examined the energy cost of a 52 minute yoga session that included sun salutation, non-sun salutation standing poses, and sitting/lying poses. The authors did not specify which style was used in this study. The mean energy expenditure was $3.2 \pm 1.1 \mathrm{kcal} / \mathrm{min}$, which was equivalent to $2.5 \pm 0.8$ metabolic equivalents (METS). This reflects a light-intensity form of physical activity, when light-intensity physical activity is defined using the commonly accepted threshold of 1.5 to $<3.0$ METS. Moreover, this study reported that this energy expenditure would be equivalent to walking at a speed of $3.2 \mathrm{~km} / \mathrm{hr}$ ( 2.0 $\mathrm{mph}$.

The style used in most studies that have examined the energy cost of yoga has been Hatha or other restorative styles of yoga. These styles of yoga focus mostly on poses for relaxation and the holding of postures, ${ }^{9}$ which may contribute to the relatively low energy expenditure observed in these studies. An alternative style is Vinyasa yoga, which is a more rigorous style of yoga and 
involves the subject moving continuously through poses versus holding poses. ${ }^{9}$ The flow and continuous movement in Vinyasa yoga practice may yield greater energy expenditure than restorative styles of yoga. However, the metabolic cost of Vinyasa yoga has not been extensively examined.

One of the few studies to examine the Vinyasa style of yoga reported that the energy cost was equivalent to 6.7 METS. ${ }^{23}$ Moreover, it was reported that this style of yoga could result in a cardiovascular stimulus through a combination of anaerobic and aerobic movement patterns. However, there are limitations to this study that should be considered that may impact our understanding of the energy expenditure resulting from Vinyasa yoga. Vinyasa yoga is dynamic and involves movement from pose to pose. In contrast, Carrol et al. ${ }^{23}$ described their form of yoga as including both dynamic and isometric movements, which suggests that the style of yoga was not Vinyasa. Moreover, the results were reported in a research abstract that was presented at a professional conference; however, these results have not been published in a research manuscript that has undergone peer review. Thus, it appears that additional research is needed to understand the energy cost of Vinyasa yoga, which includes whether the energy cost is comparable to other forms of physical activity that are commonly recommended for weight control. 


\subsection{SPECIFIC AIMS AND HYPOTHESES}

The specific aims of this study were:

1. To compare the energy expenditure $(\mathrm{kcal} / \mathrm{min}$ and $\mathrm{kcal} / \mathrm{kg} / \mathrm{min})$ of a Vinyasa yoga session to a bout of walking at a self-selected pace and a bout of walking at a matched heart rate (matched to the yoga session).

Hypothesis: It was hypothesized that energy expenditure of Vinyasa yoga would exceed the energy expenditure of a bout of walking at a self-selected pace and a bout of walking at a matched heart rate (matched to the yoga session).

2. To compare the heart rate response of a Vinyasa yoga session to a bout of walking at a self-selected pace and a bout of walking at a matched heart rate (matched to the yoga session).

Hypothesis: It was hypothesized that heart rate of Vinyasa yoga would be greater than the heart rate during of a bout of walking at a self-selected pace, but by design would not be greater than the heart rate during a bout of walking at a matched heart rate (matched to the yoga session).

3. To compare the rating of perceived exertion (RPE) in response to a Vinyasa yoga session to a bout of walking at a self-selected pace and a bout of walking at a matched heart rate (matched to the yoga session).

Hypothesis: It was hypothesized that RPE of Vinyasa yoga would be greater than the RPE during of a bout of walking at a self-selected pace and a bout of walking at a matched heart rate (matched to the yoga session). 


\subsection{CLINICAL SIGNIFICANCE}

Moderate intensity physical activity, primarily in the form of aerobic physical activity, is currently recommended within the contexts of weight control interventions. However, those forms of physical activity may not be appealing to all adults seeking to prevent weight gain or to engage in weight loss practices, which may limit engagement in these forms of physical activity. Yoga is a popular form of physical activity; however, there is a need to better understand whether yoga can be effective for the prevention of weight gain or treatment of obesity. An important research step is to understand the energy cost of yoga, particularly Vinyasa yoga. If shown to result in significant energy expenditure that is comparable to or exceeds the energy expenditure of more traditional forms of physical activity typically recommended for weight control (e.g. brisk walking), this may result in this form of yoga being recommended as an acceptable form of physical activity for weight control. Currently, none of the American College of Sports Medicine clinical recommendations for weight control include yoga as a viable form of physical activity.

In addition to the potential energy cost of Vinyasa yoga that contributes to overall energy expenditure, there may be additional health benefits of this form of physical activity that can be especially beneficial within the context of improved weight control. While not the focus of this study, these benefits may include decreased stress, ${ }^{10,11}$ a mitigation of pain, ${ }^{12-14}$ enhanced mood and diminished depression, ${ }^{15,16}$ increased flexibility, ${ }^{17,18}$ and enhanced sleep, ${ }^{19,20}$ and these may contribute to improved weight control. Moreover, adults with obesity may experience additional health benefits from yoga that include reductions in resting blood pressure and heart rate. ${ }^{22}$ Thus, there is a need for additional research to support the inclusion of yoga as a viable form of physical activity within the context of weight control. 


\subsection{REVIEW OF THE LITERATURE}

Physical activity is an important behavior that has been shown to improve numerous healthrelated outcomes. Extensive reviews of the literature conducted for the United States Surgeon's Report on Physical Activity and Health ${ }^{3}$ and the Physical Activity Guidelines for Americans ${ }^{2}$ has confirmed that there is significant scientific evidence to support the health benefits of physical activity. These health benefits include effects on risk factors such as lipids, blood pressure, glucose, insulin, and others. Physical activity has also been shown to be inversely associated with the presence of numerous chronic diseases that include, but are not limited to, cardiovascular disease, diabetes, a variety of forms of cancer, and musculoskeletal disorders, with a growing body of literature showing relationships with healthy aging and brain health. Physical activity has also been shown to be inversely associated with all-cause mortality and mortality due to numerous chronic conditions. Thus, physical activity is a key lifestyle behavior that needs to be a focus of public health approaches to improve health and reduce the burden of chronic disease.

Despite the known health benefits of physical activity, there are gaps in the scientific evidence that warrant further investigation. For example, the vast majority of research has focused on aerobic (e.g., walking) and resistance forms of physical activity, with few studies comparing these forms of physical activity to other forms of physical activity. Thus, it is unclear if other forms of physical activity should be promoted as having similar health benefits as 
aerobic or resistance forms of physical activity. Moreover, engagement in these commonly studied forms of physical activity (aerobic and resistance exercise) is less than optimal, which likely minimizes the public health impact. ${ }^{24}$

An alternative form of physical activity that is currently popular in the United States and many other countries throughout the world is yoga. ${ }^{8,9}$ As described below, there is a growing body of literature to document the potential health benefits of yoga. Thus, this study is focused on expanding the scientific evidence to support yoga as a viable form of physical activity that may improve health, particularly within the context of weight control.

\section{$2.1 \quad$ YOGA}

Yoga is a broad term used to describe mental, physical and spiritual disciplines which originated in ancient India. Rooted in Hindu philosophy, the word Yoga means "yoke," "to join," or "to unite”. 8 It is now translated into different styles and interpretations from what the ancient practice was at its inception. While Yoga has deep-rooted philosophical pieces including meditation and chanting, it is the asanas (or poses) that have evolved in the Western culture as a form of physical activity. Due to the gentleness of the asanas and how they are performed in one spot on the floor without costly equipment, yoga has been made popular among many different ages, movement abilities and special needs. ${ }^{11}$

Yoga can be done in several forms, often called "styles." Restorative styles, such as Hatha, focus on poses for relaxation, the holding of postures, and overall encourages more subject rest. ${ }^{8,9}$ As described below, there is evidence to support the role of yoga in alleviating negative health outcomes. 


\subsubsection{Stress, Depression, Anxiety, Mood}

Michalsen et al. ${ }^{11}$ evaluated the potential effects of yoga on perceived stress and associated psychological outcomes in mentally distressed women. A controlled prospective study was conducted in 24 self-referred women (age $=37.9 \pm 7.3$ years) who perceived themselves as emotionally distressed. Subjects participated in a 3-month study with randomization to a yoga group ( $\mathrm{N}=16)$ or a wait-list control group $(\mathrm{N}=8)$. Yoga consisted of attendance at 90 -minute yoga sessions twice per week. Compared to wait-list group, women who participated in the yogatraining demonstrated significant improvements in perceived stress $(\mathrm{p}<0.02)$, state and trait anxiety ( $\mathrm{p}<0.02$ and $\mathrm{p}<0.01$, respectively), well-being $(\mathrm{p}<0.01)$, vigor $(\mathrm{p}<0.02)$, fatigue $(\mathrm{p}<0.02)$, depression $(\mathrm{p}<0.05)$ and physical well-being $(\mathrm{p}<0.01)$. Salivary cortisol decreased significantly after participation in a yoga class $(\mathrm{p}<0.05)$. These results indicate that women suffering from mental distress who participated in a 3-month yoga intervention showed significant improvements on measures of stress and psychological outcomes.

$\mathrm{Li}$ and Goldsmith ${ }^{10}$ conducted a systematic review that examined the effect of yoga on stress and anxiety. This review focused on the results of studies reporting on the role of yoga in improving the signs and symptoms of stress and anxiety. Of 35 trials addressing the effects of yoga on anxiety and stress, 25 noted a significant decrease in stress and/or anxiety symptoms when a yoga intervention was implemented. For the 10 studies that did not find an anxietyrelated effect, 2 studies did not find a significant effect of yoga but reported trends that favored yoga, and in 1 of these studies only the mediation component was included without the inclusion of yoga poses. The remaining 8 studies did not include direct measures of anxiety or stress, but rather included biomarkers or other indirect measures of stress and anxiety. 
Within the review conducted by Li and Goldsmith, ${ }^{10} 14$ of the 35 studies reported biochemical and physiological markers of stress and anxiety including the stress hormones cortisol, melatonin, and Dehydroepiandrosterone (DHEA) and the neurotransmitter gammaaminobutyric acid (GABA). Other indirect measures of anxiety included blood pressure, heart rate, and respiratory function (forced expiratory volume, respiratory rate and oxygen consumption). Of the 14 studies reporting biomarkers and physiological markers, 4 reported significant decreases in cortisol levels, 1 reported significant increases in melatonin levels, 1 reported positive responses in heart rate variability and 1 reported a significant improvement in levels of GABA. The remaining 7 studies reporting biomarkers did not find a significant difference in these levels between control and yoga groups after intervention.

Woolery et al. ${ }^{16}$ examined the effects of a short-term yoga intervention on mood in mildly depressed young adults on a college campus. Young adults pre-diagnosed with mild levels of depression were randomly assigned to a yoga intervention or a wait-list control group. Twenty-eight students, ages 18 to 29 attended two 1-hour yoga classes per week for 5 consecutive weeks. Main outcome measures included the Beck Depression Inventory, State-Trait Anxiety Inventory, Profile of Mood States, and morning cortisol levels. Independent t-tests comparing the yoga and control groups at baseline indicated no group differences in depression, anxiety, interest in learning yoga, motivation to attend yoga classes, or expected benefits from learning yoga. Assessments occurred at baseline, midway through the intervention, and postintervention. Repeated measures analysis of variance showed a significantly greater reduction in depression in yoga compared to the control group $(\mathrm{p}<0.001)$. Post-hoc comparisons indicate that these improvements in yoga compared to control occurred at both midway through the intervention and were maintained by the end of the intervention. A similar pattern emerged for 
trait anxiety, with the yoga group subjects reporting decreased anxiety compared to controls $(\mathrm{p}<0.001)$. Morning cortisol levels were also assessed, with no significant differences observed in morning cortisol levels in yoga compared to control.

Uebelacker et al. ${ }^{15}$ reviewed the evidence for the efficacy of yoga for depression and possible mechanisms by which yoga may influence depression. This literature review examined eight controlled trials; 5 trials studied individuals with clinical depression and 3 trials studied individuals with elevated depression symptoms. Five of these trials compared yoga to control interventions, with four of these studies reporting that reductions in depression or depressive symptoms favor the yoga intervention, with the other study not presenting results from statistical analysis comparing the interventions. Yoga was not found to be superior in trials that compared yoga to medication, aerobic exercise, or full vs. partial engagement in yoga. While these findings appear to suggest that yoga may be a viable treatment option for the treatment of depression, these trials varied in the styles of yoga used, and yoga did not appear to be superior to other forms of treatment for depression (e.g., medication, aerobic exercise).

\subsubsection{Pain}

Galantino et al. ${ }^{12}$ conducted a pilot study to evaluate a 6-week yoga protocol on low back pain. Twenty-two subjects between the ages of 30 and 65 with chronic low back pain were randomized to a yoga intervention or to the wait-list control group. Subjects received yoga practice for one-hour, twice a week, for six weeks delivered by a certified yoga instructor. While improvements in flexibility and disability favored the yoga versus wait-list control, these did not

reach statistical significance. The investigators attributed this to the pilot nature of this study, which was not adequately powered to detect these differences with a sample of 22 subjects. 
However, this study provides some evidence of the potential influence of yoga on reducing chronic low back pain.

Sherman et al. ${ }^{14}$ conducted a randomized control trial comparing yoga to a self-care book for chronic low back pain. Two-hundred twenty two (228) adults with chronic low back pain were randomized to 12 weekly classes of yoga $(\mathrm{N}=92)$, conventional stretching exercises ( $\mathrm{N}=91)$, or a self-care book $(\mathrm{N}=45)$. Back-related functional status, measured by the modified Roland Disability Questionnaire, and self-reported discomfort of pain were the primary outcomes. Twelve-week outcomes favored the yoga group compared to the self-care group for function ( $<<0.001)$ and pain symptoms $(\mathrm{p}<0.001)$, and at 26 weeks function for the yoga group remained superior compared to self-care $(\mathrm{p}<0.001)$. However, yoga was not superior to conventional stretching exercises in this study. This study indicates that yoga is more effective than self-care for managing chronic low back pain; however, it may not be more effective than conventional stretching exercises. Thus, yoga may be a viable alternative, but is not more effective, than conventional stretching exercises for treatment of back pain.

In addition to chronic back pain, yoga has also been studied for its effects on pain associated with osteoarthritis. Ghasemi et al. ${ }^{13}$ studied the effects of 8 weeks of Hatha yoga exercises on women with knee osteoarthritis. The subjects included 30 women with knee osteoarthritis who voluntarily participated in this experimental study and were divided into a control group ( $\mathrm{N}=15)$ and a yoga group $(\mathrm{N}=15)$. The yoga group received 60-minute sessions of yoga, 3 times a week and for 8 weeks conducted by a professional yoga trainer and supervised by a physical therapist. Each yoga session included asana (movement), pranayama (breathing), and meditation (relaxation) components. Pain and symptoms were significantly improved in yoga compared to control. Moreover, there were significant increases in daily activity, sports, and 
spare-time activities in yoga compared to control, along with improvements in quality of life. This study shows promise in the use of yoga to improve the management of pain in patients with knee osteoarthritis.

\subsubsection{Flexibility}

Flexibility is an important component of health-related fitness. Kawade ${ }^{17}$ studied the effect of yoga on flexibility among 60 college aged women aged 18-20. This study compared yoga to a control group. The yoga group received one-hour of daily yoga; however, a limitation of this study is that the length of the intervention period was not reported. Flexibility was measured by a standard sit-and-reach test, which at baseline was not significantly different between control (9.8 \pm 4.6 inches) and yoga (6.2 \pm 6.1 inches). After the treatment period sit-and-reach was greater in yoga $(14.5 \pm 12.7$ inches) compared to control $(9.8 \pm 4.6$ inches $)(\mathrm{p}<0.05)$. An additional limitation of this study is that the statistical analysis included t-tests to examine differences between control and yoga at both pre- and post-intervention without adjusting the p-value for multiple comparisons or rather than using a repeated measures statistical analysis procedure. Despite the limitations of this study, results suggest that yoga may be an effective method of increasing flexibility in college-aged women.

Tekur et al. ${ }^{18}$ examined spine flexibility in patients with chronic low back pain through a short-term intensive residential yoga program with physical exercise on pain and spinal flexibility in subjects with chronic low-back pain. This study examined 80 subjects (males: $\mathrm{N}=43$, females: $\mathrm{N}=37$ ) with chronic low-back pain. Subjects were randomly assigned to a group that performed yoga or a control group that performed physical exercise for a period of 1-week within a residential program. Yoga consisted of asanas (physical postures) designed for back 
pain, pranayamas (breathing practices), meditation, and didactic and interactive sessions on philosophical concepts of yoga. The control group practiced physical exercises under the supervision of a physiatrist and also received didactic and interactive sessions on lifestyle change. The groups were matched for intervention time and attention. Spine flexibility was assessed using a goniometer. There was a significantly greater improvement in spine flexibility measures in the yoga group compared to the control group for spinal flexion ( $p=0.008$; effect size 0.146), spinal extension ( $p=0.002$; effect size 0.251$)$, right lateral flexion ( $p=0.059$; effect size 0.006$)$; and left lateral flexion $(p=0.006$; effect size 0.171$)$. In addition, this study examined pain-related outcomes using the Oswestry Disability Index and there was a significant reduction in the yoga group compared to the control group ( $p=0.01$; effect size 1.264). This intervention found that the yoga program resulted in greater improvements in spine flexibility and reduced pain-related disability in patients with chronic low back pain compared to a physical exercise regimen.

\subsubsection{Sleep}

Mustian et al. ${ }^{20}$ conducted a multi-site, randomized controlled trial to evaluate yoga for its effects on sleep quality among cancer survivors. Four-hundred ten cancer survivors with moderate or greater sleep disruption were examined between 2 and 24 months after surgery, chemotherapy and/or radiation therapy. Subjects were randomized to standard care or standard care plus a 4week yoga intervention. Sleep quality was assessed by using the Pittsburgh Sleep Quality Index and actigraphy. Yoga demonstrated greater improvements in global sleep quality, subjective sleep quality, daytime dysfunction, wake after sleep onset, sleep efficiency, and reduced medication use $(\mathrm{p}=0.05)$ compared to standard care. 
Khalsa ${ }^{19}$ studied yoga as a treatment for chronic insomnia in a population consisting of sleep-onset and/or sleep-maintenance insomnia. Subjects maintained sleep-wake diaries during a pretreatment 2-week baseline and a subsequent 8-week intervention, in which they practiced the treatment on their own, following a single in-person training session with brief in-person and telephone follow-ups. The Kundalini yoga style was used, which emphasizes meditation and breathing techniques in addition to postures, with sessions ranging from 30 to 45 minutes daily for a period of 8 weeks. Sleep efficiency, total sleep time, total wake time, sleep onset latency, wake time after sleep onset, number of awakenings, and sleep quality measures were derived from sleep-wake diary entries and were averaged in 2-week intervals. Of the 40 subjects recruited to participate in this study, 20 subjects completed the 8 week intervention and provided complete data. There was a significant improvement in total wake time $(\mathrm{p}<0.001)$, total sleep time $(\mathrm{p}<0.001)$, sleep efficiency $(\mathrm{p}<0.001)$, sleep onset latency $(\mathrm{p}=0.003)$, and wake time after sleep onset $(\mathrm{p}<0.001)$. There was no difference in the findings for those subjects performing 30 versus 45 minutes of yoga. The results of this study indicate that the yoga treatment resulted in statistically significant improvements in subjective sleep measures in patients with chronic insomnia.

\subsubsection{Summary}

Collectively, the research suggests that yoga may be an effective lifestyle behavior for a variety of health-related outcomes that include stress, depression, anxiety, mood, pain, flexibility, and sleep. However, while promising, caution should be exercised with regard to these studies fully demonstrating the effectiveness of yoga for a number of reasons. These include that some studies included small sample sizes, the short-term nature of these studies, the failure of some studies to 
include appropriate control groups, the lack of most of these studies to include alternative forms of exercise as a comparison to yoga, and the varying styles of yoga that were included in these studies. Thus, additional research is warranted to fully understand the health benefits of yoga as it pertains to the outcomes described here.

\subsection{BODY WEIGHT REGULATION AND OBESITY}

The prevalence of obesity (BMI $\geq 30 \mathrm{~kg} / \mathrm{m}^{2}$ ) has nearly doubled over the past 30 years. ${ }^{4}$ This is of significant public health concern because of the association between excess body weight and numerous chronic diseases that include diabetes, cardiovascular disease, and some forms of cancer. ${ }^{5,6}$ Physical activity is an important component of interventions to regulate body weight and to treat obesity, ${ }^{7}$ and physical activity may also reduce the risk of chronic diseases commonly associated with obesity. ${ }^{2}$

Physical activity has been shown to contribute to weight loss. While the mean weight loss from physical activity is typically less than $3 \mathrm{~kg},{ }^{6,725}$ there also appears to be a doseresponse relationship with greater amounts of physical activity producing greater weight loss., ${ }^{2,7}$ Weight loss resulting from interventions combining dietary restriction plus physical activity has been shown to be greater than the weight loss achieved with dietary restriction alone.,7 Moreover, physical activity has been shown to be a significant predictor of long-term weight loss and prevention of weight regain., ${ }^{2,7}$

Of interest is that the majority of studies examining the role of physical activity in body weight regulation has been focused on traditional aerobic (walking, etc.) and resistance (weight training) forms of physical activity. However, there is some evidence that yoga may also be a 
form of physical activity that will influence body weight regulation, and therefore may be an effective modality for the prevention and treatment of obesity. For example, several studies have reported an association between yoga and reduction in weight and BMI. ${ }^{26-29}$ There are a number of potential pathways by which yoga may impact body weight regulation (Figure 1), and a brief review of the literature to highlight these potential pathways is included below.

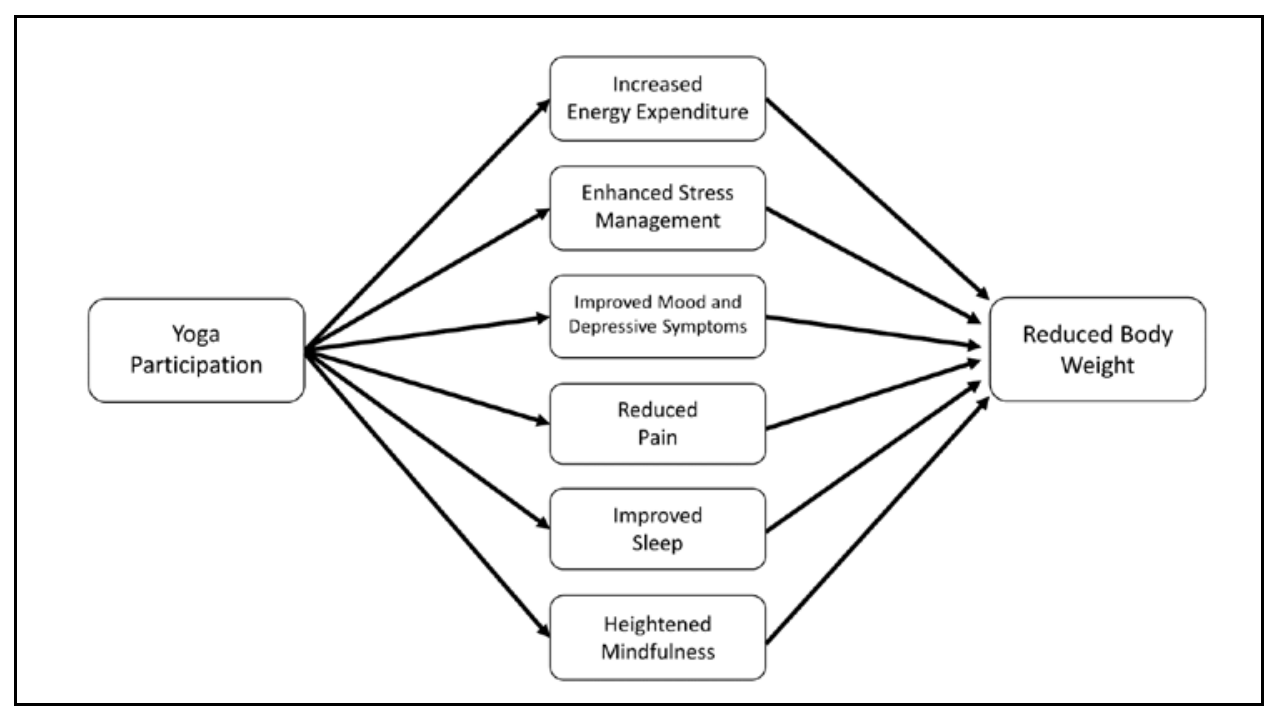

Figure 1. Pathways by which Yoga may be Associated with Reduced Body Weight

\subsubsection{Energy Expenditure and Obesity}

Weight gain results from an imbalance between energy intake and energy expenditure, where energy intake exceeds energy expenditure. Therefore, one strategy to combat weight gain and induce weight loss is to increase energy expenditure. Increasing participation in physical activity is one common strategy to increase energy expenditure, and a limited number of studies have examined the energy expenditure resulting from engaging in yoga. 
Key to yoga being considered a form of physical activity that may be effective for weight control is its ability to significantly contribute to an increase in energy expenditure. However, there has been limited research conducted to examine the energy cost of yoga. In one of the few studies that has been conducted, Hagins et al. ${ }^{22}$ examined the energy cost of a 52 minute yoga session that included sun salutation, non-sun salutation standing poses, and sitting/lying poses. The mean energy expenditure was $3.2 \pm 1.1 \mathrm{kcal} / \mathrm{min}$, which was equivalent to $2.5 \pm 0.8$ metabolic equivalents (METS). This reflects a light-intensity form of physical activity, when lightintensity physical activity is defined using the commonly accepted threshold of 1.5 to $<3.0$ METS. Moreover, this study reported that this energy expenditure would be equivalent to walking at a speed of $3.2 \mathrm{kph}(2.0 \mathrm{mph})$.

The style used in most studies that have examined the energy cost of yoga has been Hatha or other restorative styles of yoga. These styles of yoga focus mostly on poses for relaxation and the holding of postures, ${ }^{8}$ which may contribute to the relatively low energy expenditure observed in these studies. An alternative style of yoga is Vinyasa yoga, which is a more rigorous style of yoga and involves the subject moving continuously through poses versus holding poses. ${ }^{8,9}$ The flow and continuous movement in Vinyasa practice may yield greater energy expenditure than restorative styles of yoga. However, the metabolic cost of Vinyasa yoga has not been extensively examined.

One of the few studies to examine the Vinyasa style of yoga reported that the energy cost was equivalent to 6.7 METS. ${ }^{23}$ Moreover, it was reported that this style of yoga could provide a result in a cardiovascular stimulus through a combination of anaerobic and aerobic movement patterns. However, there are limitations to this study that should be considered that may limit our understanding of the energy expenditure resulting from Vinyasa yoga. Vinyasa yoga is 
dynamic and involves movement from pose to pose. Carrol et al. ${ }^{23}$ described the form of yoga used in their research as including both dynamic and isometric movements, which suggests that the style of yoga studied was not Vinyasa. Moreover, the results reported by investigators were in a research abstract that was presented at a professional conference; however, these results have not been published in a research manuscript that has undergone peer review. Thus, it appears that additional research is needed to understand the energy cost of Vinyasa yoga, which includes whether the energy cost is comparable to other forms of physical activity that are commonly recommended for weight control.

\subsubsection{Stress Management and Obesity}

Tranchant et al. ${ }^{30}$ reported on the relationship between changes in BMI and stress in a sample of 96 women with obesity (BMI $30.8 \mathrm{~kg} / \mathrm{m}^{2}$ ). Subjects underwent a diet program of $800 \mathrm{kcal} / \mathrm{day}$ and completed an online assessment including measures of stress response and depression. Assessments occurred at baseline and between 8-16 weeks of treatment (mean=12.5 weeks after baseline). There was a significant change in BMI from baseline to the follow-up assessment $30.8 \pm \mathrm{kg} / \mathrm{m}^{2}$ to $\left.27.4 \pm 4.7 \mathrm{~kg} / \mathrm{m}^{2} ; \mathrm{p}<0.0001\right)$. Stress response and depression improved significantly at by the follow-up assessment $(\mathrm{p}<0.0001)$. There was a significant association between reduced BMI and a reduction in stress $(\mathrm{r}=0.41 ; \mathrm{p}<0.0001)$.

Richardson et al. ${ }^{31}$ examined the association between obesity and stress in a population vulnerable to stress, low-income women. They examined cross-sectional data from 101 women including BMI, 24-hour diet recalls, qualitative data from questions on perceived stress and information from questionnaires on eating behaviors. The results indicated that perceived stress 
was both positively and directly associated with severe obesity $(\beta=0.26, p=0.007)$, emotional eating $(\beta=0.50, \mathrm{p}<0.001)$ and uncontrolled eating $(\beta=0.38, \mathrm{p}<0.001)$.

Several studies support the belief that yoga has a down-regulating effect on both the hypothalamic-pituitary-adrenal axis (HPA) and the sympathetic nervous system (SNS). These systems are activated as a response to a stressor leading to several physiological effects including the release of cortisol. Over time, the repeated firing of the HPA axis and SNS can lead to dysregulation of the system and ultimately impact obesity. ${ }^{32}$ Studies show that yoga decreases levels of salivary cortisol, which may suggest that yoga reduces the effect on the HPA/SNS axis response to stress. ${ }^{33}$ This mechanistic pathway may be important in understanding how yoga may influence body weight regulation.

\subsubsection{Mood \& Depressive Symptoms and Obesity}

There is a substantial body of literature illustrating an association between obesity and mood disorders. This is confirmed in a recent review by Mansur et al. ${ }^{34}$ Moreover, there is evidence that individuals with negative mood may respond less favorably to weight loss interventions.

For example, Trief et al. ${ }^{35}$ examined the relationships between weight loss and both depression symptoms and stress in 257 adults with metabolic syndrome. Measures of weight, depression, and perceived stress were taken at baseline, 6 months, 1 and 2 years. Subjects were grouped as having elevated depressive symptoms ( $\geq 16$ on the Center for Epidemiology Studies Depression Scale) or non-elevated depressive symptoms ( $<16$ on the Center for Epidemiology Studies Depression Scale). Percent weight loss 6 months (-2.87 vs. $-5.32 \%, p=0.010), 1$ Year (-3.31 vs. 6.24\%, $\mathrm{p}=0.28)$, and 2 years $(-3.09$ vs. $-5.88 \%, \mathrm{p}=0.066)$ was lower in subjects with elevated depressive symptoms compared to those with non-elevated depressive symptoms. Moreover, a 
smaller percentage of subjects with elevated depressive symptoms achieved $\geq 5 \%$ weight loss (6 months: $26.9 \%$ vs. $45.9 \%, \mathrm{p}=0.011$; Year 1: $28.8 \%$ vs. $46.6 \%$, $\mathrm{p}=0.034$; Year 2: $29.2 \%$ vs. 47.6\%, $\mathrm{p}=0.038$ ). Subjects were also grouped as high stress ( $\geq 23$ on the Perceived Stress Scale) and low stress ( $<23$ on the Perceived Stress Scale). Subjects with high stress achieved a lower percent of weight loss than those with low lower stress at 6 months (-3.17 vs. $-5.61 \%, p=.009$ ), Year $1(-3.40$ vs. $-6.77 \%, \mathrm{p}=0.007)$ and Year $2(-2.94$ vs. $-6.56 \%, \mathrm{p}=0.013)$. Similar to what was observed with depression, those with high stress were less likely to lose $\geq 5 \%$ weight than those with low stress at 1 year (29.0\% vs. $50.0 \%, \mathrm{p}=.008)$ and 2 years $(28.8 \%$ vs. $50.7 \%, \mathrm{p}=.011)$. Thus, it may be important to have behavioral weight loss interventions that also are effective at treating negative mood, which includes elevated levels of depressive symptoms, to improve weight loss in response to these interventions.

Patients with obesity also tend to have higher prevalence of binge eating disorder (BED), and this is of concern because patients with BED are more likely to drop out of weight loss interventions and have greater weight regain following initial weight loss. ${ }^{36}$ A recent review has also shown that there is an association between BED and the presence of negative mood, sadness, tension and instability of emotions, ${ }^{37}$ and this confirms findings from prior reviews on this topic. ${ }^{36}$ Thus, it may be clinically important to treat these negative emotions prior to or within the context of interventions to improve weight loss in adults with obesity, particularly in those with BED.

As presented earlier in this literature review, there is evidence that yoga may be an effective intervention option to address negative mood. Thus, this may be a potential pathway by which yoga can be an effective intervention option for the prevention of weight gain or the treatment of obesity. 


\subsubsection{Pain and Obesity}

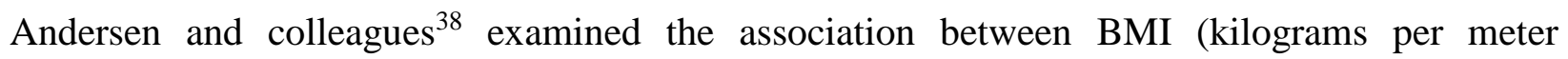
squared) and reports of significant knee, hip, and back pain using data from a nationally representative sample (from the Third National Health and Nutrition Examination Survey) of adults aged 60 years or older in the United States. Data on weight, BMI, and the presence of significant knee, hip and back pain was available on 5,724 adults. Prevalence of knee, hip, and back pain were 21\%, 14\%, and 22\%, respectively. Data also showed higher prevalence of pain with increased BMI. Prevalence estimates for knee (underweight $12.1 \%$ to obesity class III 55.7\%), hip (underweight $10.4 \%$ to obesity class III 23.3\%), and back (underweight 20.2\% to obesity class III 26.1\%) pain increased with increased BMI.

Masheb et al. ${ }^{39}$ examined whether the presence of pain is associated with suboptimal weight loss outcomes in weight management programs. This secondary data analysis used data from a randomized controlled trial with 481 subjects in a weight loss intervention. This data included pain categories where subjects indicated the severity and location of their pain. Results indicated that subjects with severe pain lost significantly less weight $(-0.01 \mathrm{~kg}, 95 \% \mathrm{CI}=-1.5$, 1.2) in comparison to those with moderate pain $(-1.9 \mathrm{~kg}, 95 \% \mathrm{CI}=-2.5,-1.3)$ or no reported pain $(-2.1 \mathrm{~kg}, 95 \% \mathrm{CI}=-3.3,-1.0)$.

Pain has been shown to be inversely associated with physical activity. ${ }^{40,41}$ Given that physical activity is an important intervention strategy for increasing energy expenditure, which may play a role in the prevention of weight gain or assist with weight loss, addressing pain should be a relevant component of intervention strategies. As presented earlier in this literature review, there is evidence that yoga may be an effective intervention option to address pain. Thus, if yoga is effective at reducing pain, this may facilitate engagement in physical activity 
that can play an important role in the prevention of weight gain or in the treatment of obesity.

\subsubsection{Sleep and Obesity}

There is evidence to support that poor sleep is inversely associated with weight gain and the prevalence of obesity. For example, data from the Nurses’ Health Study showed women who reported sleeping 5 or fewer hours per night were at greater risk for weight gain and in general weighed more compared with women who slept 7-8 hours per night. ${ }^{42}$ These associations remained significant after inclusion of important covariates and were not affected by adjustment for physical activity or dietary consumption. These findings suggest that decreased sleep duration is associated with a modest increase in future weight gain and obesity.

Studies have also linked weight gain associated with short sleep to changes in appetiteregulating hormones such as leptin and ghrelin. Spiegel and colleagues ${ }^{43}$ examined a randomized, two-year, cross-over, clinical study to determine if partial sleep curtailment alters appetite regulation. Researchers measured daytime profiles of leptin and ghrelin as well as subjective ratings of appetite and hunger. The intervention consisted of two days of sleeprestriction and two days of sleep-extension under controlled conditions. Sleep restriction was associated with reductions in leptin (decrease 18\%, p=0.04), elevations in ghrelin (increase 28\%, $\mathrm{p}<0.04$ ), increased hunger (increase 24\%, $<<0.01$ ), and increased appetite (increase 23\%, $\mathrm{p}=0.01$ ), especially for high-calorie and carbohydrate-rich foods.

Earlier in this literature review evidence was presented that suggests that yoga may be an effective intervention option to treat poor sleep. Thus, given the association between poor sleep and body weight regulation as presented above, addressing poor sleep through yoga may be an 
effective intervention to optimize body weight regulation that may result in prevention of weight gain or enhanced weight loss.

\subsubsection{Mindfulness and Obesity}

Mindfulness is a heightening of awareness to actions and is the opposite of operating automatically or absent-mindedly. Tapper et al. ${ }^{44}$ explored the efficacy of a mindfulness-based weight loss intervention for women. Subjects included 62 females with a mean BMI of $31.57 \pm 6.06 \mathrm{~kg} / \mathrm{m}^{2}$ and a mean age of $41 \pm 13$ years who were randomized to a mindfulness intervention or control group. The mindfulness intervention included attendance at four 2-hour mindfulness education workshops and also included homework that was complete between these sessions. The control group was instructed to not modify their current normal behaviors, which included their diet. Measures of BMI, physical activity and mental health were taken at baseline and both 4 and 6 months later. Intervention subjects showed a significant increase in physical activity compared to controls $(\mathrm{p}<0.05)$ but no significant differences between the mindfulness and control groups for weight loss or mental health outcomes. However, only $74 \%$ of subjects in the intervention group attended at least 2 out of the 4 workshops. Thus, data were also analyzed excluding those subjects $(\mathrm{N}=7)$ who reported 'never' applying the workshop principles. Results of these analyses showed that mindfulness resulted in significantly greater increase in physical activity $(\mathrm{p}<0.05)$ and a significantly greater reduction in BMI $(\mathrm{p}<0.05)$ compared to control.

Mason et al. ${ }^{45}$ also examined the implementation of a mindfulness-based, weight loss intervention on eating sweet foods and fasting glucose levels. Adults with obesity ( $\mathrm{N}=194$, age $=47.0 \pm 12.7$ years, $\mathrm{BMI}=35.5 \pm 3.6$ ) participated in a 5.5 month intervention that included diet and exercise, with randomization for the intervention to include or not include mindfulness 
training. The mindfulness intervention included eating meditations and addressed physical hunger, level of fullness, and taste satisfaction. The intervention also included subjects being taught to implement "mini-meditations" before eating and the awareness of food cravings and other emotional triggers that lead to eating. The use of these mindfulness strategies was also assessed. The mindfulness group had a greater increase in mindful eating from baseline to 12 months compared to the non-mindfulness group. Results also showed that both groups had similar reductions in the percent of calories consumed as "sweets" from baseline to both 6 months; however, the non-mindfulness group had an increase in the percent of calories consumed as "sweets" from 6 to 12 months compared to the mindfulness intervention ( $p=0.035)$. Moreover, the non-mindfulness group also had a significant increase in fasting glucose from baseline to 12 months $(\mathrm{p}=0.035)$. Unfortunately, data on whether there were differences in weight loss between the mindfulness and non-mindfulness group were not presented.

As presented earlier, patients with obesity also tend to have higher prevalence of binge eating disorder (BED), and this is of concern because patients with BED are more likely to drop out of weight loss interventions and have greater weight regain following initial weight loss. ${ }^{36}$ Kristeller et al ${ }^{46}$ conducted a 4 month intervention with 150 adults who were overweight or obese with BED randomized to mindfulness-based eating awareness training, psychoeducational/cognitive-behavioral intervention, or control. Both the mindfulness-based eating awareness training and psycho-educational/cognitive-behavioral intervention showed decreases in BED compared to control, with no significant difference between mindfulness-based eating awareness training and psycho-educational/cognitive-behavioral intervention. It was also reported that the amount of practice in mindfulness was predictive of weight loss ( $\mathrm{r}=0.38$, $\mathrm{p}=<0.05)$. 
The practice of most forms of yoga include components of mindfulness, which typically uses mindfulness to draw attention to breath and body position. ${ }^{8,9}$ As presented above, there is some evidence that mindfulness may be effective for modifying physical activity, eating behaviors, and potentially body weight. Thus, the inclusion of mindfulness training within yoga may be another potential pathway by which yoga may influence prevention of weight gain or weight loss.

\subsection{VINYASA YOGA}

Vinyasa yoga is a more rigorous style of yoga than restorative styles such as Hatha yoga, and involves the subject moving continuously through poses versus holding poses. ${ }^{8,9}$ The flow and continuous movement in Vinyasa practice may potentially yield an increase in energy expenditure, which may assist in body weight regulation, and it may also provide a cardiovascular fitness benefit. However, the metabolic cost of Vinyasa yoga has not been well examined, leaving a gap in the research that is focused on yoga. However, if research shows that Vinyasa yoga has a comparable metabolic cost when compared to other forms of physical activity, this may suggest that recommendations should be expanded to include yoga as a viable option in weight management strategies, either from a prevention or treatment perspective.

Yoga can be modified to accommodate many different populations making it accessible to nearly everyone regardless of age, gender, physical fitness or level of obesity. Although the more restorative styles of yoga have value and may be more effective for certain populations or needs, these styles may not be the best genres to study for their obesity prevention and weight loss strategies because of their time spent in a sedentary position. This is because these restorative 
styles of yoga involve holding poses and do not move rapidly from one pose to the next, which reduces the heart rates response and very likely reduces the energy expenditure compared to more vigorous styles of yoga.

More vigorous styles of yoga are typically termed "power yoga" or "athletic yoga", which is a phrase used to describe styles of yoga that are more aerobically demanding. ${ }^{9}$ However, these forms of yoga have undergone less scientific study than restorative forms of yoga. Power yoga also places a greater emphasis on strength and vigor than restorative forms of yoga. Vinyasa yoga, which means "to flow with breath", ${ }^{9}$ is a style of yoga typically considered within the category of "power yoga" or "athletic yoga". Vinyasa yoga is also referred to as "flow yoga” because it links the poses together as though the subject is performing a dance, and the breath is used in conjunction with the movements. For example, the practitioner inhales into one pose and exhales to travel to the next. This breath allows the individual to keep calm, potentially getting the more meditative aspects of the practice, while traveling with ease from pose to pose. Thus, it might be expected that given these components, Vinyasa yoga that includes moving from pose-to-pose would yield relatively high metabolic cost, potentially making it comparable in energy expenditure to other forms of physical activity that aerobic in nature.

As described above, there have been few studies that have examined the energy cost of Vinyasa yoga. One of the few studies that has reported on this style of yoga showed that the energy cost was equivalent to 6.7 METS. ${ }^{23}$ However, this study had limitations. This study did not appear to necessarily examine true Vinyasa yoga, because as described by the investigators, it included both dynamic and isometric movements, which does not guarantee that the style of yoga was Vinyasa. Without a detailed explanation of the poses performed and sequencing done, we cannot verify that validity of the style performed in this research. Moreover, this study 
provides limited data on how true Vinyasa yoga compares in energy expenditure to other common forms of physical activity, such as walking. Thus, it appears that additional research of Vinyasa yoga is needed, which includes a better understanding of the energy cost of this style of yoga, which is the focus of this proposed study. If found to elicit a relatively high energy cost compared to walking, this may suggest that Vinyasa yoga may be a viable form of physical activity to be considered in interventions to prevent weight gain and to treat overweight and obesity. 


\subsection{METHODS}

This study compared the energy expenditure during acute bouts of Vinyasa yoga and walking in adults. This research was conducted at the University of Pittsburgh, Physical Activity and Weight Management Research Center. The relative energy expenditure ( $\mathrm{kcal} / \mathrm{kg} / \mathrm{min})$ and the absolute energy expenditure $(\mathrm{kcal} / \mathrm{min})$ during these acute periods of exercise were the primary outcome variables evaluated in this study. In addition, heart rate and perceived exertion was assessed between acute bouts of Vinyasa yoga and walking.

\subsection{SUBJECTS}

Thirty healthy adults without mobility limitations and with experience engaging in yoga were recruited to participant in this study. Eligibility and ineligibility criteria are described below.

Eligibility criteria included the following:

1. Age $18-55$ years

2. Prior yoga experience with Vinyasa yoga including familiarity with the names of the foundational poses

3. Familiarity with treadmill walking

Ineligibility criteria included the following: 
1. Previous diagnosis of conditions requiring additional medical clearance (i.e. cancer, heart disease, or Type I, or Type II diabetes).

2. Presence of a medical condition that may limit one's ability to perform yoga or walk to exercise (i.e. orthopedic limitations or severe arthritis). Subjects were required to walk briskly for exercise to complete the walking trials, and any orthopedic limitation would limit the ability of the individuals to complete these components.

4. Currently taking prescription or over-the-counter medications that affect heart rate (i.e. anti-depressants, beta-blockers, bronchodilators/antihistamines, calcium channel blockers, digitalis, and thyroid medications).

5. Women who are currently pregnant, as indicated by self-report during the phone screen.

\subsection{RECRUITMENT AND SCREENING PROCEDURES}

Potential subjects were recruited using the following: 1) fliers posted locally, 2) online recruiting resources (i.e. Craigslist), and 3) fliers distributed to the students enrolled in yoga courses in the Department of Health and Physical Activity at the University of Pittsburgh. Interested individuals were instructed to contact the principle investigator at the number provided in the recruitment materials. Individuals whom responded to these recruitment advertisements were read a description of the study and completed a brief telephone screening after providing verbal consent. Screening information included questions regarding demographic background, physical health, and medical history to determine initial eligibility. To ensure confidentiality, identifiable information (name, contact information, etc.) was not collected until it was determined that the 
individual appeared to be eligible based on this initial telephone screening. Individuals who were found to be eligible following the telephone screening were invited to attend an orientation session where additional details of the study were provided, informed consent obtained, and additional eligibility screening occurred.

\subsection{ORIENTATION AND FAMILIARIZATION SESSION}

Upon arrival to the University of Pittsburgh for the in-person orientation session, the Principal Investigator reviewed the study protocol and allowed individuals an opportunity to answer any questions before signing an informed consent document. After obtaining written informed consent, subjects underwent familiarization trials to treadmill walking and yoga using the protocols described below. If subjects were unable to tolerate the metabolic facemask or demonstrate that they were able to perform both treadmill walking and yoga, they would not have been eligible to participate in this study, and no data would have been collected beyond this point. This was not an issue and all 30 subjects who passed the phone screen were able to complete the orientation process.

The subjects underwent an orientation to the treadmill to practice the walking session, as well as to familiarize them with the equipment. The subject was orientated to the metabolic equipment by fitting the facemask that was required to be worn. Subjects were read a script regarding the proper technique that was required during the treadmill session. Subjects were then asked to step onto the treadmill set at $2.0 \mathrm{mph}$ and given instruction and feedback on proper walking technique from the investigators. The subjects then underwent an orientation to the yoga session to practice the yoga protocol. Subjects were read a script regarding the proper technique 
that was required for participation during the yoga session. This included a checklist of techniques that they had to demonstrate competency in, including the positions that would be cued in the yoga session (Appendix C). This portion of the orientation also included instruction in minor modifications that would be required to two yoga poses in order to accommodate the testing equipment. This orientation session lasted $<10$ minutes in duration. The subjects wore the metabolic testing equipment throughout the orientation session to ensure their comfort with the mask.

\subsection{ASSESSMENT PROCEDURES}

The following measures were used to describe the sample:

1. Weight: Weight was assessed to the nearest $0.1 \mathrm{~kg}$ on a digital scale and with the subject clothed in a hospital gown. The mean of 2 measures differing by $\leq 0.5 \mathrm{~kg}$ was used for data analysis, with a maximum of 3 measures taken. If after 3 measures this criterion was not achieved, or if multiple pairs of measures did not meet this criterion, the mean of all the measures were used for data analysis.

2. Height: Height was be measured to the nearest $0.1 \mathrm{~cm}$ using a wall-mounted stadiometer (Perspective Enterprises; Portage, MI) with shoes removed. The mean of 2 measures differing by $\leq 0.5 \mathrm{~cm}$ were used for data analysis, with a maximum of 3 measures taken. If after 3 measures this criterion was not achieved, or if multiple pairs of measures met this criterion, the mean of all the measures were used for data analysis. 
3. Body Mass Index (BMI): BMI was computed from these measures of weight and height and computed as $\mathrm{kg} / \mathrm{m}^{2}$.

4. Body Composition: Body composition was assessed using bioelectrical impedance analysis (BIA). Measurements were taken in a lightweight hospital gown following the removal of all jewelry from the right side of the body. Electrodes were placed in four locations: (1) midpoint of styloid processes at the right wrist; (2) joint between the knuckles of the index and middle fingers of the right hand; (3) midpoint of the lateral and medial malleoli of the right ankle; and (4) joint at the base of the great and second toes on the right foot. The subject was instructed to lie in a supine position. Electrical impedance of body tissues was determined by obtaining measurements of resistance and reactance using a calibrated ohm meter. Data was used to estimate body composition using the equation proposed by Segal et al. ${ }^{47}$

5. Self-report Physical Activity: The modified Paffenbarger Physical Activity Questionnaire $^{48}$ measured physical activity by assessing the average number of flights of stairs climbed each day, and amount and duration of brisk walking completed for the sole purpose of exercise or transportation each day. This questionnaire also queries on sport, recreation, and/or fitness activities. Trained personnel administered this questionnaire as an interview. Data was used to estimate energy expenditure (kcal/week) in leisure-time physical activity. 


\subsection{EXPERIMENTAL DESIGN}

The proposed study utilized a modified crossover design, with subjects serving as their own control. All subjects completed a Vinyasa yoga session, Heart Rate Matched Walk session, and Self-Selected Intensity Walk session. The modified crossover design used the following order of exercises because the Heart Rate Matched Walk session needed to follow the Yoga session in all exercise sequences. Therefore, subjects were randomized to one of the following experimental conditions that varied the order of these acute exercise sessions, with each exercise session being 60 minutes in duration:

1. Experimental Condition 1
a. Orientation and Assessment Session
b. Vinyasa Yoga Session
c. Heart Rate Matched Walk Session
d. Self-Selected Intensity Walk Session

2. Experimental Condition 2
a. Orientation and Assessment Session
b. Vinyasa Yoga Session
c. Self-Selected Intensity Walk Session
d. Heart Rate Matched Walk Session

3. Experimental Condition 3
a. Orientation and Assessment Session
b. Self-Selected Intensity Walk Session
c. Vinyasa Yoga Session
d. Heart Rate Matched Walk Session 


\subsection{EXPERIMENTAL CONDITIONS}

\subsubsection{Vinyasa Yoga Session}

Prior to the yoga trial, subjects were instructed to wear traditional exercise clothing that allowed freedom of movement to complete the yoga session. Of importance, subjects were notified that they needed to complete this trial in bare feet on a yoga mat (that was provided). Upon arrival, the subjects were fitted with a Polar heart rate monitor (Port Washington, NY) and the Oxycon Mobile metabolic testing equipment (San Diego, CA) and were instructed to sit quietly in a chair for 5 minutes to allow for acclimatization to the equipment. During this time, the subjects were given a brief overview of the protocol.

During the yoga session, participants performed the yoga sequence that followed a video that contained the instructor's cues along with a person on the screen demonstrating the sequence. Participants were asked to follow the cues of the instructor but to take any modifications of the poses that they would normally take during their own practice (in order to make the pose easier or more accessible). Staff tracked whether each yoga pose was performed in a manner consistent with the video or whether the individual modified the pose, and the

degree of modification, using the data sheet that is included in Appendix D. There were only 5 participants who did not use at least one modification of a pose. The yoga sequence is described in Appendix E, and the types and frequency of modifications made to this standard sequence are provided in Appendix F.

The sequence used for the yoga session is detailed in Appendix E and is based off of the Journey into Power sequence from Baron Baptiste ${ }^{9}$. During this time, the investigator observed 
if the subject maintained proper form. If criteria for proper form are not met during the yoga session, the investigator corrected the subject using verbal cues.

Measures of heart rate, oxygen consumption $\left(\mathrm{VO}_{2}\right)$, carbon dioxide production $\left(\mathrm{VCO}_{2}\right)$, respiratory exchange ratio (RER) and pulmonary ventilation (Ve) were obtained continuously each minute. Immediately following this 60 -minute Vinyasa yoga session the subject rated their perceived exertion across the entire yoga session using the Borg 15-category scale.

\subsubsection{Heart Rate Matched Walking Session}

To determine the target heart rate for this trial, minute-by-minute heart rates obtained during the yoga exercise trial were averaged across each 15 minute period. These heart rates were used to determine the intensity of this walking trial. For example, the average heart rate from minutes 0 15 of the yoga session were matched for the first 15 minutes of treadmill walking, and heart rates 16-30 were matched for the second 15 minutes of treadmill walking (minutes 16-30), etc.

The subject was fitted with the equipment and instructed to sit quietly in a chair for 5 minutes to allow for acclimatization to the equipment. To begin the 60-minute trial, the treadmill was initially set at a speed of $2.0 \mathrm{mph}$ and $0 \%$ incline and the subject stepped on the treadmill and was instructed to begin walking. Every 30 seconds, the speed of the treadmill was increased by $0.2 \mathrm{mph}$ until the subject achieved the target heart rate ( $+/-5 \mathrm{bpm})$, which was matched to the Vinyasa yoga session as described above. After the initial 5 minutes, adjustments were made to the speed of the treadmill as needed throughout the 15 minute period to maintain the heart rate within this targeted range. Once the participant reached a speed of $4.0 \mathrm{mph}$, adjustments were made to the incline of the treadmill (in $0.5 \%$ increments) in order to maintain the matched heart rate. This protocol (Appendix F) was repeated each 15 minutes to adjust for the change in heart 
rate across the 60 minute session. The speed and incline information on the treadmill display was covered to eliminate any potential influence that this would have on the subject. Measures of heart rate, $\mathrm{VO}_{2}, \mathrm{VCO}_{2}$, RER, Ve were obtained continuously and averaged across each minute. Immediately following this 60-minute walking session the subject rated their perceived exertion across the entire walking session using the Borg 15-category scale.

\subsubsection{Self-Selected Intensity Walking Session}

Upon arrival, the subject was fitted with the equipment and instructed to sit quietly in a chair for 5 minutes to allow for acclimatization to the equipment. To begin the 60-minute trial, the treadmill was initially set at a speed of $1.0 \mathrm{mph}$ and $0 \%$ incline and the subject stepped onto the treadmill and was instructed to begin walking. The speed and incline information on the treadmill display was covered to eliminate any potential bias or influence on the self-selected walking speed. During the initial 5 minutes, the subject was given a signal to the investigator at 30 second intervals to increase, decrease, or maintain the speed of the treadmill to elicit their perceived comfortable self-selected brisk walking pace. These adjustments were made at 0.5 mph increments. The speed of the treadmill achieved at 5 minutes was maintained through the remainder of the experimental session unless the subject requested to increase or decrease the speed. The subject was asked if they desired a change their walking speed at 5 minute intervals, and the walking speed was increased or decreased at $0.5 \mathrm{mph}$ increments upon request to allow for an appropriate self-selected walking speed that was comfortable for the subject. Measures of heart rate, $\mathrm{VO}_{2}, \mathrm{VCO}_{2}$, RER and $\mathrm{Ve}$ were obtained continuously and averaged across each 
minute. Immediately following the 60 -minute walking session the subject rated their perceived exertion across the entire walking session using the Borg 15-category scale.

\subsection{INSTRUMENTATION}

\subsubsection{Indirect Calorimetry}

Measures of $\mathrm{VO}_{2}, \mathrm{VCO}_{2}, \mathrm{RER}$, and Ve were taken during the Vinyasa yoga and walking trials using a portable metabolic cart (Oxycon Mobile, CareFusion, San Diego, CA). Subjects breathed into a fitted facemask that allowed for both mouth and nasal breathing. Measures of $\mathrm{VO}_{2}, \mathrm{VCO}_{2}$, RER and Ve were obtained continuously and averaged across each minute to provide an assessment of energy expenditure. The primary outcome in this study was energy expenditure per minute ( $\mathrm{kcal} / \mathrm{min})$, which was determined from $\mathrm{VO}_{2}(\mathrm{l} / \mathrm{min})$ using the non-protein caloric equivalent based on the RER to adjust for energy substrate utilization. Energy expenditure relative to body weight $(\mathrm{kcal} / \mathrm{min} / \mathrm{kg}$ ) and the metabolic equivalent (MET) was also calculated by the Oxycon Mobile system.

\subsubsection{Heart Rate Monitoring}

Heart rate (not heart rhythm) was monitored continuously using a Polar heart rate monitor (Port Washington, NY) strapped firmly to the subject's skin on their chest below the sternum and pectoralis muscles $\left(5^{\text {th }}\right.$ intercostal space) during all trials. 


\section{$3.8 \quad$ STATISTICAL ANALYSIS}

Statistical analyses was performed using SPSS version 21.0. Statistical significance was set at $\mathrm{p}<0.05$. Descriptive analyses were performed for height, weight, BMI, \% body fat, and leisuretime physical activity. Comparison of descriptive data between men and women were compared using an independent t-test (height, weight, BMI, \% body fat) or the Mann-Whitney U test (leisure-time physical activity).

To examine Specific Aims 1, 2, and 3 separate one-way repeated measures analysis of variance (ANOVA) were performed for the energy expenditure (total kcal, kcal/min, METS), heart rate, RPE, and RER using the mean data across the 60 minutes experimental sessions (Vinyasa yoga, heart rate matched walking, self-selected intensity walking). The data were reanalyzed using only the initial 45 minutes from each of the experimental sessions also using a within-subject repeated measures ANOVA. To determine if gender influenced the pattern of results, post-hoc exploratory analysis was performed using a two way ANOVA (Gender X Exercise) for both the 60 minute and the 45 minute of the exercise sessions.

The assumption of normality was tested using the Shapiro-Wilkes test and assumption of sphericity were tested using Mauchly's test. If the assumption of sphericity was not met the Greenhouse-Geisser adjustment was used. When appropriate, post hoc comparisons (dependent t-tests) were made with the p-valued adjusted using the Bonferonni procedure for multiple comparisons to determine which exercises were significantly different from the others. 


\subsection{POWER ANALYSIS}

Hill and colleagues ${ }^{49}$ suggested that a $50 \mathrm{kcal} /$ day could offset weight gain in about $90 \%$ of the population. A $50 \mathrm{kcal} / \mathrm{h}$ difference between any of the two activities would equate to 0.83 $\mathrm{kcal} / \mathrm{min}$. A recent study conducted in our laboratory indicated that the standard deviation for walking on a treadmill to be approximately $1.3 \mathrm{kcal} / \mathrm{min}$. These data were used to estimate the sample to detect an effect size of 0.64 using a 2-tailed statistical test, with the p-value adjusted to allow for 2 comparisons (yoga vs. heart rate matched treadmill walking, yoga vs. self-selected walking pace on treadmill). We used G*Power to determine our sample size estimates. It was determined that to detect an effect size of 0.64 , with power set at 0.80 , and the type I error rate set at $\mathrm{p}=0.025$ using the Bonferonni correction, that 26 subjects (13 men and 13 women) would be required. Therefore, to allow for potential attrition, a final sample of 30 subjects (15 men and 15 women) were recruited and underwent the experimental trials. 


\subsection{RESULTS}

The purpose of this study was to compare energy expenditure and ratings of perceived exertion during a yoga session and treadmill walking in healthy individuals. This study utilized a randomized cross-over design and the results from the study are presented in the following sections.

\subsection{PARTICIPANTS}

Telephone screening calls were conducted for a total of 32 individuals. Of these potential participants, 30 were found to be eligible based on the inclusion/exclusion criteria. All of the 30 individuals who were eligible based on the telephone screen attended the orientation session, were consented, and became participants in the study. One individual who was screened was going to turn 56 years of age during testing. Another individual who passed the screening chose not to participate and withdrew because he did not want to shave his face for the exercise sessions to allow for proper fitting of the metabolic system. During the experimental sessions, equipment failure occurred resulting in incomplete data for 2 participants (both females). For one participant during the self-walk session, the battery in the portable metabolic system failed, requiring a change in the battery at the 43 minute time point of the session. For the other participant, during the heart rate matched session, the telemetry failed at the start of the session 
which disabled the metabolic system from collecting accurate data. Therefore, these 2 participants have been excluded from the final analysis, resulting in complete data for 28 participants (15 males, 13 females).

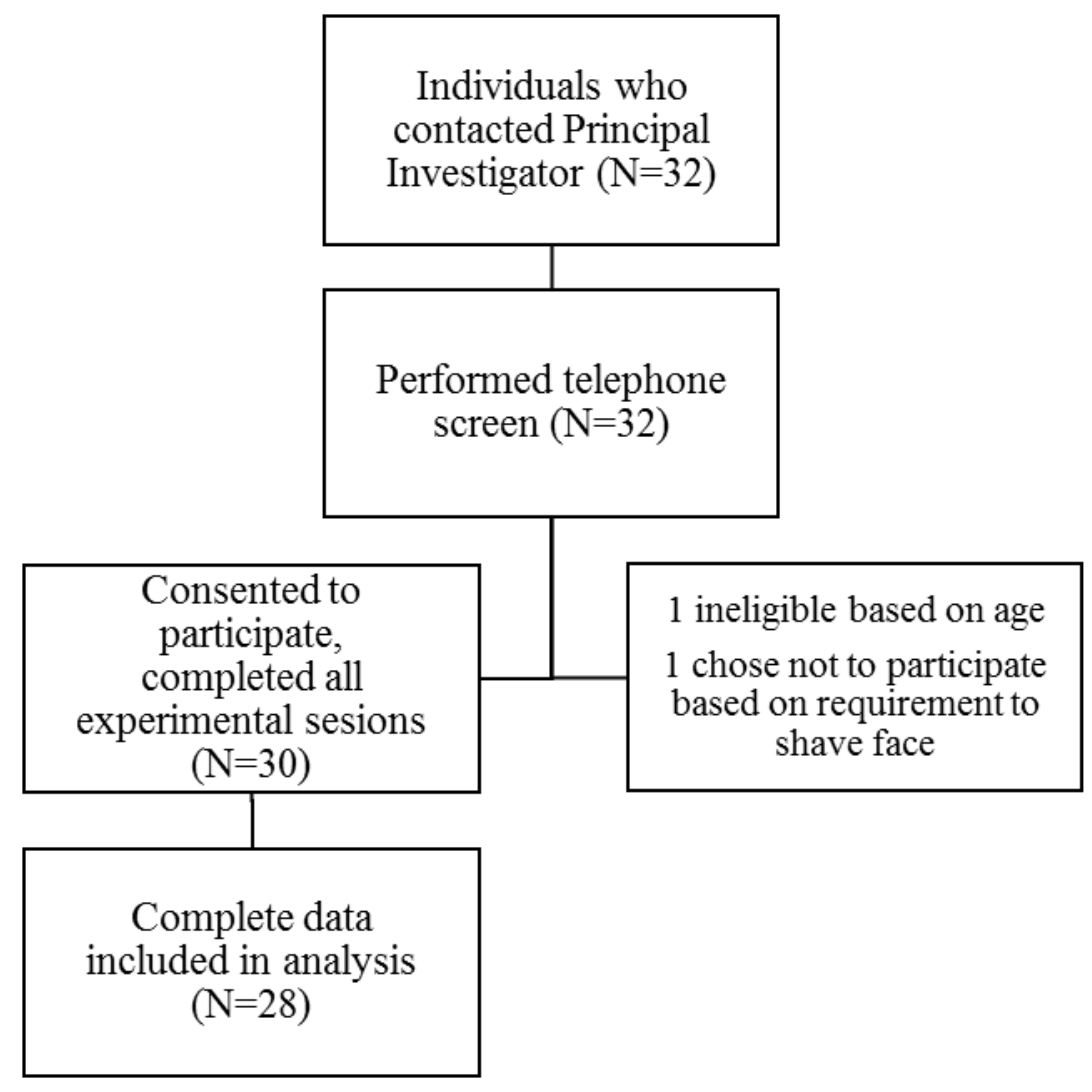

Figure 2. Participant Recruitment and Enrollment

Descriptive statistics for both the complete sample of 30 participants and of the 28 individuals whom were used for data analysis (mean \pm standard deviation) are shown in Table 1. The total sample $(\mathrm{N}=30)$ had a mean age of $31.0 \pm 8.3$ and a body mass index of $24.7 \pm 3.3$. The 
male participants had a significantly higher body weight $(83.4 \pm 14.0 \mathrm{~kg})$ than female participants $(62.0 \pm 10.1 \mathrm{~kg})(\mathrm{p}<0.001)$. However, the male participants had a significantly lower body fat percentage $(17.7 \pm 6.1 \%)$ compared to females $(25.1 \pm 7.1 \%)(\mathrm{p}=<0.001)$. The sample of 28 participants who provided complete data and were included in the final analyses had demographic characteristics that were similar to the total sample.

Table 1. Participant Descriptive Variables

\begin{tabular}{|c|c|c|c|c|}
\hline Variable & $\begin{array}{l}\text { Total } \\
(\mathrm{N}=28)\end{array}$ & $\begin{array}{c}\text { Men } \\
(\mathrm{N}=15)\end{array}$ & $\begin{array}{l}\text { Women } \\
(\mathrm{N}=13)\end{array}$ & p-value* \\
\hline Age (years)** & $31.0 \pm 8.3$ & $29.8 \pm 7.4$ & $32.4 \pm 9.4$ & 0.424 \\
\hline Height $(\mathrm{cm})^{* *}$ & $171.8 \pm 9.9$ & $178.9 \pm 6.1$ & $163.5 \pm 6.3$ & $<0.001$ \\
\hline Weight $(\mathrm{kg})^{* *}$ & $73.5 \pm 16.3$ & $83.4 \pm 14.0$ & $62.0 \pm 10.1$ & $<0.001$ \\
\hline BMI $\left(\mathrm{kg} / \mathrm{m}^{2}\right)^{* *}$ & $24.7 \pm 3.3$ & $25.9 \pm 2.8$ & $23.2 \pm 3.4$ & 0.026 \\
\hline Percent Body Fat** & $21.1 \pm 7.5$ & $17.7 \pm 6.1$ & $25.1 \pm 7.1$ & 0.006 \\
\hline $\begin{array}{l}\text { Physical Activity } \\
\text { (kcal/week)*** }\end{array}$ & $\begin{array}{c}3289.3 \\
(2025.5,4497.9)\end{array}$ & $\begin{array}{c}3782.5 \\
(2246.0,5336.0)\end{array}$ & $\begin{array}{c}3074.0 \\
(1945.0,4305.3)\end{array}$ & 0.475 \\
\hline \multicolumn{5}{|c|}{$\begin{array}{l}* \text { p-value is for the comparison between men and women } \\
* * \text { Data presented as mean } \pm \text { standard deviation } \\
* * * \text { Data presented as median }\left(25^{\text {th }} \text { percentile, } 75^{\text {th }} \text { percentile }\right)\end{array}$} \\
\hline
\end{tabular}

\subsection{ANALYSIS OF DATA BY SPECIFIC AIM}

\subsubsection{Specific Aim 1: Energy expenditure across exercise conditions}

A within-subject repeated measures ANOVA showed a significant difference in total energy expenditure (kcal) across the 60 minute activity period between the experimental conditions 
$(p<0.001)$ (Table 2). Post-hoc analyses revealed a significantly lower energy expenditure in the yoga session compared to both the heart rate matched session (difference $=82.2 \pm 42.1 \mathrm{kcal}$; $\mathrm{p}<0.001$ ) and the self-selected walk session (difference $=44.1 \pm 70.0 \mathrm{kcal} ; \mathrm{p}=0.003$ ), and a lower energy expenditure in the self-selected walk session compared to the heart rate matched session (difference $=38.1 \pm 75.3 \mathrm{kcal} ; \mathrm{p}=0.012$ ). Exploratory analysis showed no significant interaction by gender $(\mathrm{p}=0.165)$ (Table 3). The energy expenditure (kcals per minute) across the 60 minutes of each exercise session is shown in Figure 3.

Data were also analyzed to examine difference in metabolic equivalents (METs) between the three experimental conditions $(\mathrm{p}<0.001)$. Post-hoc analyses revealed significantly lower METs in the yoga session compared to both the heart rate matched session (difference $=1.1 \pm$ 0.5 METs; $\mathrm{p}<0.001$ ) and the self-selected walk session (difference $=0.7 \pm 0.9$ METs; $\mathrm{p}=<0.002$ ), and a lower energy expenditure in the self-selected walk session compared to the heart rate matched session (difference $=0.5 \pm 1.0$ METs; $\mathrm{p}=0.016$ ). Exploratory analysis showed no significant interaction by gender $(\mathrm{p}=0.399)$ (Table 3$)$.

The data were reanalyzed using only the initial 45 minutes from each of the experimental sessions, which excluded the restorative component of the yoga session. A within-subject repeated measures ANOVA showed a significant difference in total energy expenditure (kcal) across the 45 minute activity period between the experimental conditions $(\mathrm{p}<0.001)$ (Table 4$)$. However, post-hoc analyses revealed a significantly lower energy expenditure in the yoga session compared to the heart rate matched session (difference $=72.0 \pm 37.5 \mathrm{kcal} ; \mathrm{p}<0.001$ ), but not compared to the self-selected walk session (difference $=8.8 \pm 53.9 \mathrm{kcal} ; \mathrm{p}=0.393$ ). Energy expenditure was also significantly lower in the self-selected walk session compared to the heart 
rate matched session $(63.2 \pm 60.8 \mathrm{kcal} ; \mathrm{p}<0.001)$. Exploratory analysis showed no significant interaction by gender $(\mathrm{p}=0.094)$ (Table 5$)$.

There was also a significant difference in METs across the 45 minute activity period between the experimental conditions $(\mathrm{p}<0.001)$ (Table 4). Post-hoc analyses revealed a significantly lower metabolic equivalent in the yoga session compared to the heart rate matched session (difference $=1.3 \pm 0.6$ METs; $\mathrm{p}<0.001$ ), but not compared to the self-selected walk session (difference $=0.2 \pm 0.9$ METs; $\mathrm{p}=0.650$ ). Metabolic equivalent was also significantly lower in the self-selected walk session compared to the heart rate matched session $(1.1 \pm 1.0$ METs; $\mathrm{p}<0.001)$. Exploratory analysis showed no significant interaction by gender $(\mathrm{p}=0.357)$ (Table 5). 
Table 2. Experimental Session (1-60 minutes) with Post-Hoc Analysis (N=28)

\begin{tabular}{|c|c|c|c|c|}
\hline Variable & $\begin{array}{c}\text { Self-Selected } \\
\text { Walking Pace } \\
\text { Trial }\end{array}$ & $\begin{array}{l}\text { Matched Heart } \\
\text { Rate Response } \\
\text { Walking Trial* }\end{array}$ & Yoga Trial & p-Value \\
\hline $\begin{array}{l}\text { Heart rate } \\
\text { (beats / minute) }\end{array}$ & $103.6 \pm 16.3$ & $113.5 \pm 16.1$ & $112.7 \pm 16.9$ & 0.001 \\
\hline \begin{tabular}{l|l} 
Difference with Self-Selected \\
Walking Pace Trial
\end{tabular} & ----- & $\begin{array}{c}9.9 \pm 13.7 \\
(p=0.001)^{* *}\end{array}$ & $\begin{array}{c}9.2 \pm 14.6 \\
(p=0.003)^{* *}\end{array}$ & \\
\hline $\begin{array}{l}\text { Difference with Matched } \\
\text { Heart Rate Response Trial } \\
\end{array}$ & $\begin{array}{l}---- \\
\end{array}$ & ----- & $\begin{array}{c}0.8 \pm 2.9 \\
(p=0.166)\end{array}$ & \\
\hline Energy Expenditure (kcal) & $329.2 \pm 82.1$ & $367.3 \pm 93.7$ & $285.1 \pm 71.6$ & $<0.001$ \\
\hline $\begin{array}{l}\text { Difference with Self-Selected } \\
\text { Walking Pace Trial }\end{array}$ & ----- & $\begin{array}{c}38.1 \pm 75.3 \\
(p=0.012)^{* *}\end{array}$ & $\begin{array}{c}44.1 \pm 70.0 \\
(p=0.003)^{* *}\end{array}$ & \\
\hline \begin{tabular}{l|l} 
Difference with Matched \\
Heart Rate Response Trial \\
\end{tabular} & ----- & ----- & $\begin{array}{c}82.2 \pm 42.1 \\
(p<0.001)^{* *}\end{array}$ & \\
\hline $\begin{array}{l}\text { Energy Expenditure } \\
\text { ( kcal / minute) }\end{array}$ & $5.5 \pm 1.4$ & $6.1 \pm 1.6$ & $4.8 \pm 1.2$ & $<0.001$ \\
\hline \begin{tabular}{l|l} 
& Difference with Self-Selected \\
Walking Pace Trial
\end{tabular} & $\begin{array}{ll}---- \\
\end{array}$ & $\begin{array}{c}0.6 \pm 1.3 \\
(p=0.012)^{* *}\end{array}$ & $\begin{array}{c}0.7 \pm 1.2 \\
(p=0.003)^{* *}\end{array}$ & \\
\hline \begin{tabular}{|l|l|} 
Difference with Matched \\
Heart Rate Response Trial
\end{tabular} & $\begin{array}{ll}---- \\
\end{array}$ & ----- & $\begin{array}{c}1.4 \pm 0.7 \\
(p<0.001)^{* *}\end{array}$ & \\
\hline $\begin{array}{l}\text { Metabolic Equivalents } \\
\text { (METs / minute) }\end{array}$ & $4.4 \pm 0.7$ & $4.9 \pm 0.8$ & $3.7 \pm 0.6$ & $<0.001$ \\
\hline \begin{tabular}{l|l} 
Difference with Self-Selected \\
Walking Pace Trial
\end{tabular} & $\begin{array}{ll}---- \\
\end{array}$ & $\begin{array}{c}0.5 \pm 1.0 \\
(p=0.016) * *\end{array}$ & $\begin{array}{c}0.7 \pm 0.9 \\
(p<0.002)^{* *}\end{array}$ & \\
\hline \begin{tabular}{|l|l} 
Difference with Matched \\
Heart Rate Response Trial
\end{tabular} & ----- & ----- & $\begin{array}{c}1.1 \pm 0.5 \\
(p<0.001)^{* *}\end{array}$ & \\
\hline $\begin{array}{l}\text { Respiratory Exchange Ratio } \\
\text { (RER / minute) }\end{array}$ & $0.86 \pm 0.05$ & $0.88 \pm 0.05$ & $0.94 \pm 0.05$ & $<0.001$ \\
\hline \begin{tabular}{l|l} 
Difference with Self-Selected \\
Walking Pace Trial
\end{tabular} & $\begin{array}{ll}---- \\
\end{array}$ & $\begin{array}{c}0.02 \pm 0.05 \\
(p=0.101)\end{array}$ & $\begin{array}{c}0.08 \pm 0.05 \\
(p<0.001)^{* *}\end{array}$ & \\
\hline \begin{tabular}{|l|l} 
Difference with Matched \\
Heart Rate Response Trial
\end{tabular} & ----- & ---- & $\begin{array}{c}0.06 \pm 0.05 \\
(p<0.001)^{* *}\end{array}$ & \\
\hline $\begin{array}{l}\text { Rating of Perceived Exertion } \\
\text { (RPE) }\end{array}$ & $11.9 \pm 1.4$ & $12.9 \pm 2.0$ & $13.9 \pm 1.4$ & $<0.001$ \\
\hline \begin{tabular}{|l|l|} 
Difference with Self-Selected \\
Walking Pace Trial
\end{tabular} & ----- & $\begin{array}{c}1.0 \pm 2.1 \\
(p=0.022)\end{array}$ & $\begin{array}{c}2.0 \pm 1.6 \\
(p<0.001)^{* *}\end{array}$ & \\
\hline $\begin{array}{l}\text { Difference with Matched } \\
\text { Heart Rate Response Trial }\end{array}$ & $\begin{array}{ll}---- \\
\end{array}$ & ---- & $\begin{array}{c}1.0 \pm 1.6 \\
(p=0.002)^{* *}\end{array}$ & \\
\hline
\end{tabular}

*Matched to the heart rate of the Yoga Trial.

**Statistically significant based on critical p-value of $<0.017$ that is adjusted for 3 pairwise comparisons. 
Table 3. Comparison of heart rate, energy expenditure, metabolic equivalents, and respiratory exchange ratio between females and males across the experimental conditions during minutes 1-60 ( $N=28)$

\begin{tabular}{|c|c|c|c|c|c|c|}
\hline \multirow[t]{2}{*}{ Variable } & \multirow{2}{*}{$\begin{array}{c}\text { Self-Selected } \\
\text { Walking Pace } \\
\text { Trial } \\
\end{array}$} & \multirow{2}{*}{$\begin{array}{l}\text { Matched Heart } \\
\text { Rate Response } \\
\text { Walking Trial* }\end{array}$} & \multirow{2}{*}{$\begin{array}{l}\text { Yoga } \\
\text { Trial }\end{array}$} & \multicolumn{3}{|c|}{ p-Values } \\
\hline & & & & Gender & Measure & $\begin{array}{c}\text { Gender } \\
\text { X } \\
\text { Measure }\end{array}$ \\
\hline $\begin{array}{l}\text { Heart rate } \\
\text { (beats / minute) }\end{array}$ & & & & 0.101 & 0.001 & 0.742 \\
\hline Females $(\mathrm{N}=13)$ & $109.5 \pm 16.2$ & $118.2 \pm 14.3$ & $117.0 \pm 15.0$ & & & \\
\hline Males (N=15) & $98.3 \pm 14.9$ & $109.5 \pm 17.0$ & $109.1 \pm 18.0$ & & & \\
\hline $\begin{array}{l}\text { Energy Expenditure } \\
\text { (kcal) }\end{array}$ & & & & $<0.001$ & $<0.001$ & 0.165 \\
\hline Females $(\mathrm{N}=13)$ & $276.8 \pm 63.1$ & $292.5 \pm 48.9$ & $224.9 \pm 39.2$ & & & \\
\hline Males (N=15) & $374.5 \pm 69.6$ & $432.0 \pm 72.0$ & $337.3 \pm 47.6$ & & & \\
\hline $\begin{array}{l}\text { Energy Expenditure } \\
\text { (kcal / minute) }\end{array}$ & & & & $<0.001$ & $<0.001$ & 0.221 \\
\hline Females $(\mathrm{N}=13)$ & $4.6 \pm 1.1$ & $4.9 \pm 0.8$ & $3.7 \pm 0.7$ & & & \\
\hline Males $(\mathbf{N}=15)$ & $6.2 \pm 1.2$ & $6.2 \pm 1.2$ & $5.6 \pm 0.8$ & & & \\
\hline $\begin{array}{l}\text { Metabolic Equivalents } \\
\text { (METs / minute) }\end{array}$ & & & & 0.120 & $<0.001$ & 0.399 \\
\hline Females $(\mathrm{N}=13)$ & $4.4 \pm 0.8$ & $4.6 \pm 0.7$ & $3.5 \pm 0.5$ & & & \\
\hline Males (N=15) & $4.4 \pm 0.7$ & $5.1 \pm 0.8$ & $3.9 \pm 0.5$ & & & \\
\hline $\begin{array}{l}\text { Respiratory Exchange } \\
\text { Ratio (RER / minute) }\end{array}$ & & & & 0.210 & $<0.001$ & 0.055 \\
\hline Females $(\mathrm{N}=13)$ & $0.84 \pm 0.04$ & $0.87 \pm 0.05$ & $0.95 \pm 0.04$ & & & \\
\hline Males (N=15) & $0.88 \pm 0.05$ & $0.88 \pm 0.04$ & $0.94 \pm 0.05$ & & & \\
\hline $\begin{array}{l}\text { Rating of Perceived } \\
\text { Exertion (RPE) }\end{array}$ & & & & 0.480 & $<0.001$ & 0.472 \\
\hline Females $(\mathrm{N}=13)$ & $12.1 \pm 1.2$ & $12.8 \pm 2.3$ & $14.2 \pm 1.8$ & & & \\
\hline Males (N=15) & $11.7 \pm 1.7$ & $12.9 \pm 1.7$ & $13.5 \pm 0.7$ & & & \\
\hline
\end{tabular}

*Matched to the heart rate of the Yoga Trial. 
Table 4. Experimental Session (minutes 1-45) with Post-Hoc Analysis ( $N=28$ )

\begin{tabular}{|c|c|c|c|c|}
\hline Variable & $\begin{array}{c}\text { Self-Selected } \\
\text { Walking Pace } \\
\text { Trial } \\
\end{array}$ & $\begin{array}{l}\text { Matched Heart } \\
\text { Rate Response } \\
\text { Walking Trial* }\end{array}$ & Yoga Trial & p-Value \\
\hline $\begin{array}{l}\text { Heart rate } \\
\text { (beats / minute) }\end{array}$ & $101.8 \pm 15.3$ & $118.4 \pm 17.0$ & $118.2 \pm 17.6$ & $<0.001$ \\
\hline \begin{tabular}{l|l} 
& $\begin{array}{l}\text { Difference with Self-Selected } \\
\text { Walking Pace Trial }\end{array}$ \\
\end{tabular} & ----- & $\begin{array}{c}16.6 \pm 13.9 \\
(p=<0.001)^{* *}\end{array}$ & $\begin{array}{c}16.3 \pm 14.6 \\
(p=<0.001)^{* *}\end{array}$ & \\
\hline $\begin{array}{l}\text { Difference with Matched } \\
\text { Heart Rate Response Trial }\end{array}$ & ----- & ----- & $\begin{array}{c}0.2 \pm 3.7 \\
(p=0.796)\end{array}$ & \\
\hline Energy Expenditure (kcal) & $242.8 \pm 60.7$ & $306.0 \pm 77.6$ & $234.0 \pm 57.8$ & $<0.001$ \\
\hline $\begin{array}{l}\text { Difference with Self-Selected } \\
\text { Walking Pace Trial }\end{array}$ & ----- & $\begin{array}{c}63.2 \pm 60.8 \\
(p=<0.001)^{* *}\end{array}$ & $\begin{array}{l}8.8 \pm 53.9 \\
(p=0.393)\end{array}$ & \\
\hline \begin{tabular}{l|l} 
Difference with Matched \\
Heart Rate Response Trial
\end{tabular} & ----- & ----- & $\begin{array}{l}72.0 \pm 37.5 \\
(p<0.001)^{* *}\end{array}$ & \\
\hline $\begin{array}{l}\text { Energy Expenditure } \\
\text { (kcal / minute) }\end{array}$ & $5.4 \pm 1.3$ & $6.8 \pm 1.7$ & $5.2 \pm 1.3$ & $<0.001$ \\
\hline \begin{tabular}{l|l} 
& $\begin{array}{l}\text { Difference with Self-Selected } \\
\text { Walking Pace Trial }\end{array}$ \\
\end{tabular} & ----- & $\begin{array}{c}1.4 \pm 1.4 \\
(p=<0.001)^{* *}\end{array}$ & $\begin{array}{c}0.2 \pm 1.2 \\
(p=0.394)\end{array}$ & \\
\hline \begin{tabular}{|l|l} 
Difference with Matched \\
Heart Rate Response Trial
\end{tabular} & ----- & ---- & $\begin{array}{c}1.6 \pm 0.8 \\
(p<0.001)^{* *}\end{array}$ & \\
\hline $\begin{array}{l}\text { Metabolic Equivalents } \\
\text { (METs / minute) }\end{array}$ & $4.3 \pm 0.7$ & $5.4 \pm 0.9$ & $4.1 \pm 0.6$ & $<0.001$ \\
\hline \begin{tabular}{|l|l|} 
Difference with Self-Selected \\
Walking Pace Trial
\end{tabular} & ----- & $\begin{array}{c}1.1 \pm 1.0 \\
(p=<0.001)^{* *}\end{array}$ & $\begin{array}{c}0.2 \pm 0.9 \\
(p=0.650)\end{array}$ & \\
\hline \begin{tabular}{l|l} 
& Difference with Matched \\
Heart Rate Response Trial
\end{tabular} & ----- & ----- & $\begin{array}{c}1.3 \pm 0.6 \\
(p=<0.001)^{* *}\end{array}$ & \\
\hline $\begin{array}{l}\text { Respiratory Exchange Ratio } \\
\text { (RER / minute) }\end{array}$ & $0.87 \pm 0.05$ & $0.89 \pm 0.05$ & $0.95 \pm 0.05$ & $<0.001$ \\
\hline \begin{tabular}{l|l} 
& $\begin{array}{l}\text { Difference with Self-Selected } \\
\text { Walking Pace Trial }\end{array}$ \\
\end{tabular} & ----- & $\begin{array}{c}0.02 \pm 0.05 \\
(p=0.024)\end{array}$ & $\begin{array}{c}0.09 \pm 0.06 \\
(p=<0.001)^{* *}\end{array}$ & \\
\hline $\begin{array}{l}\text { Difference with Matched } \\
\text { Heart Rate Response Trial }\end{array}$ & ----- & ---- & $\begin{array}{c}0.02 \pm 0.05 \\
(p=<0.001)^{* *}\end{array}$ & \\
\hline
\end{tabular}

*Matched to the heart rate of the Yoga Trial.

**Statistically significant based on critical p-value of $<0.017$ that is adjusted for 3 pairwise comparisons. 
Table 5. Comparison of heart rate, energy expenditure, metabolic equivalents, and respiratory exchange ratio between females and males across the experimental conditions during minutes 1-45 ( $N=28)$

\begin{tabular}{|c|c|c|c|c|c|c|}
\hline Variable & $\begin{array}{c}\text { Self-Selected } \\
\text { Walking Pace } \\
\text { Trial }\end{array}$ & $\begin{array}{l}\text { Matched Heart } \\
\text { Rate Response } \\
\text { Walking Trial* }\end{array}$ & $\begin{array}{l}\text { Yoga } \\
\text { Trial }\end{array}$ & \multicolumn{3}{|c|}{ p-Values } \\
\hline & & & & Gender & Measure & $\begin{array}{c}\text { Gender } \\
\text { X } \\
\text { Measure }\end{array}$ \\
\hline $\begin{array}{l}\text { Heart rate } \\
\text { (beats / minute) }\end{array}$ & & & & 0.118 & 0.001 & 0.909 \\
\hline Females $(\mathbf{N}=13)$ & $107.5 \pm 15.4$ & $122.8 \pm 15.2$ & $122.6 \pm 15.7$ & & & \\
\hline Males (N=15) & $96.9 \pm 13.9$ & $114.6 \pm 18.0$ & $114.4 \pm 18.9$ & & & \\
\hline $\begin{array}{l}\text { Energy Expenditure } \\
\text { (kcal) }\end{array}$ & & & & $<0.001$ & $<0.001$ & 0.094 \\
\hline Females $(\mathrm{N}=13)$ & $204.2 \pm 46.1$ & $243.8 \pm 40.7$ & $185.5 \pm 33.1$ & & & \\
\hline Males (N=15) & $276.3 \pm 52.0$ & $360.0 \pm 59.0$ & $276.1 \pm 37.7$ & & & \\
\hline $\begin{array}{l}\text { Energy Expenditure } \\
\text { (kcal / minute) }\end{array}$ & & & & $<0.001$ & $<0.001$ & 0.076 \\
\hline Females $(\mathrm{N}=13)$ & $4.5 \pm 1.0$ & $5.4 \pm 0.9$ & $4.1 \pm 0.7$ & & & \\
\hline Males (N=15) & $6.1 \pm 1.2$ & $8.0 \pm 1.3$ & $6.1 \pm 0.8$ & & & \\
\hline $\begin{array}{l}\text { Metabolic Equivalents } \\
\text { (METs / minute) }\end{array}$ & & & & 0.125 & $<0.001$ & 0.357 \\
\hline Females $(\mathrm{N}=13)$ & $4.3 \pm 0.8$ & $5.1 \pm 0.8$ & $3.9 \pm 0.6$ & & & \\
\hline Males (N=15) & $4.3 \pm 0.7$ & $5.6 \pm 0.7$ & $4.3 \pm 0.5$ & & & \\
\hline $\begin{array}{l}\text { Respiratory Exchange } \\
\text { Ratio (RER / minute) }\end{array}$ & & & & 0.262 & $<0.001$ & 0.074 \\
\hline Females $(\mathrm{N}=13)$ & $0.84 \pm 0.04$ & $0.88 \pm 0.06$ & $0.96 \pm 0.05$ & & & \\
\hline Males (N=15) & $0.88 \pm 0.05$ & $0.90 \pm 0.04$ & $0.95 \pm 0.06$ & & & \\
\hline
\end{tabular}

*Matched to the heart rate of the Yoga Trial. 


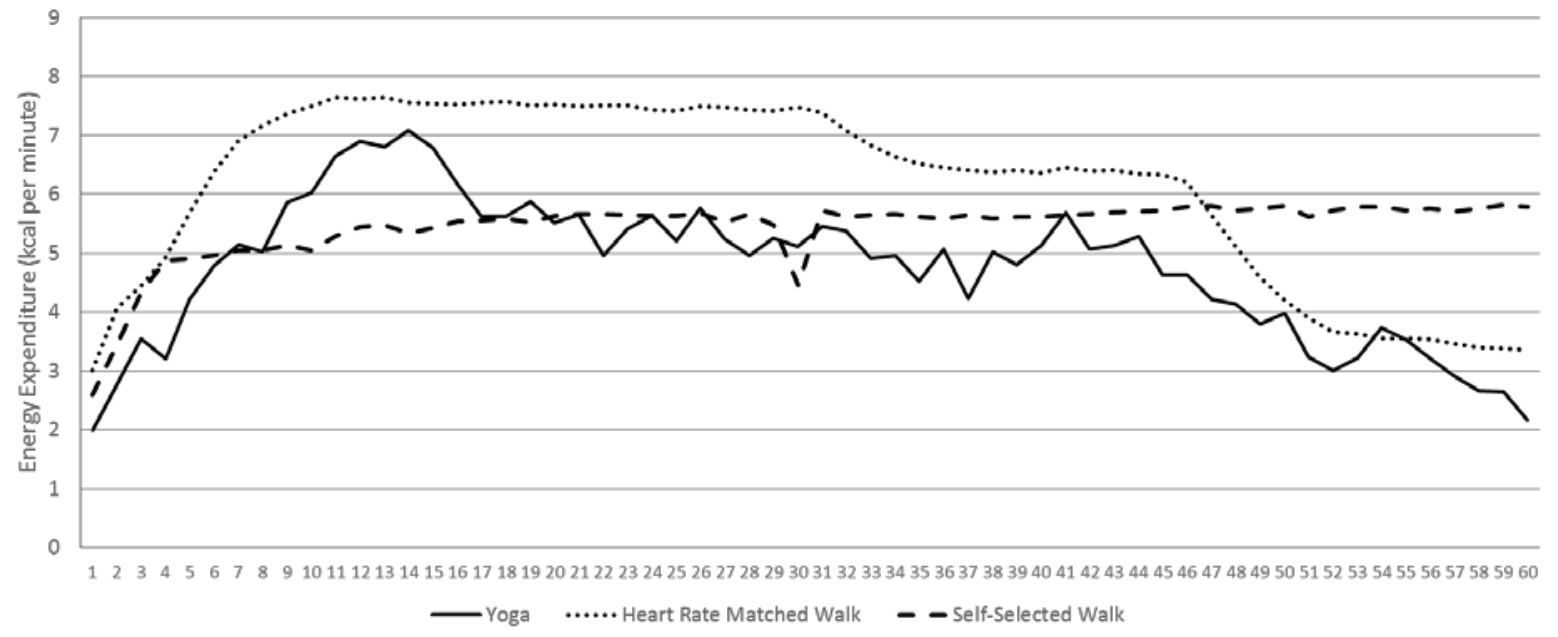

Figure 3. Energy Expenditure (kcal/min) across the Exercise Sessions

\subsubsection{Specific Aim 2: Heart rate across exercise conditions}

A within-subject repeated measures ANOVA showed a significant difference in heart rate across the 60 minute activity period between the experimental conditions ( $\mathrm{p}=0.001)$ (Table 2). Post-hoc analyses revealed a significantly lower heart rate in the self-selected walking trial compared to both the heart rate matched session (difference $=9.9 \pm 13.7 \mathrm{bpm} ; \mathrm{p}=0.001$ ) and the yoga session (difference $=9.2 \pm 14.6 \mathrm{bpm} ; \mathrm{p}=0.003$ ), and no significant difference in heart rate in the heart rate matched session compared to the yoga session $(0.8 \pm 2.9 \mathrm{bpm} ; \mathrm{p}=0.166)$. Exploratory analysis shown no significant interaction by gender $(\mathrm{p}=0.742)$ (Table 3$)$. The heart rate (beats/minute) across the 60 minutes of each exercise session is shown in Figure 4.

The data were reanalyzed using only the initial 45 minutes from each of the experimental sessions. Within-subject repeated measures ANOVA showed a significant difference in heart rate (beats/minute) across the 45 minute activity period between the experimental conditions $(p=<0.001)$ (Table 4). However, post-hoc analyses revealed a significantly lower heart rate in the 
self-walk session compared to the heart rate matched session (difference= $16.6 \pm 13.9 \mathrm{bpm}$; $\mathrm{p}<0.001$ ), and compared to the yoga session (difference $=16.3 \pm 14.6 \mathrm{bpm} ; \mathrm{p}<0.001$ ). There was no significant difference in the heart rates between the yoga session and the heart rate matched session (difference $=0.2 \pm 3.7 \mathrm{bpm} ; \mathrm{p}=0.796$ ). Exploratory analysis shown no significant interaction by gender $(\mathrm{p}=0.909)$ (Table 5$)$.

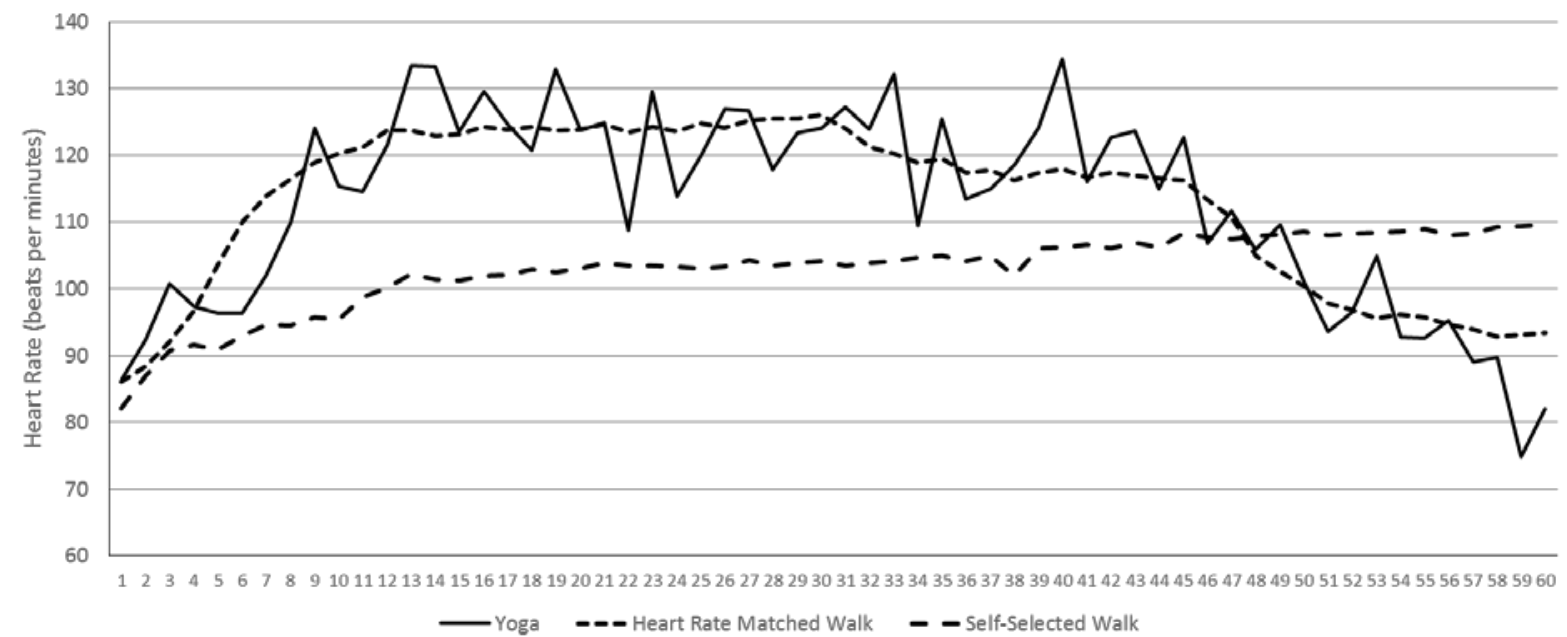

Figure 4. Heart Rate (beats/minute) across the Exercise Sessions

\subsubsection{Specific Aim 3: Ratings of perceived exertion (RPE) across exercise conditions}

A within-subject repeated measures ANOVA showed a significant difference in the ratings of perceived exertion (RPE) across the 60 minute activity period between the experimental conditions $(\mathrm{p}<0.001)$ (Table 2). The RPE for the exercise trials was found to be the following; $11.9 \pm 1.4$ for the self-selected walk session, $12.9 \pm 2.0$ for the heart rate matched session, and $13.9 \pm 1.4$ for the yoga session. This indicates a significantly lower rate of perceived exertion in 
the self-walk session compared to the yoga session (difference $=2.0 \pm 1.6$; $\mathrm{p}<0.001$ ) and the heart rate matched session compared to the yoga session (difference $=1.0 \pm 1.6 ; \mathrm{p}=0.002$ ). There was no significant difference in RPE between the heart rate matched session and the self-selected walk session (difference $=1.0 \pm 2.1 ; \mathrm{p}=0.022$ ). Exploratory analysis showed no significant interaction by gender $(\mathrm{p}=0.472)$ (Table 3 ). The RPE data was collected at the completion of the 60 minute exercise sessions and reflects the participant's perceived exertion across 60 minutes. Therefore, this data could not be analyzed for 45 minutes. 


\subsection{DISCUSSION}

The present study reports on the energy expenditure of an acute Vinyasa yoga session. It was found the across the entire 60 minute Vinyasa yoga session, mean energy expenditure was $4.8 \pm 1.2 \mathrm{kcal} / \mathrm{min}(3.7 \pm 0.6 \mathrm{METS})$. When only considering the initial 45 minutes of the Vinyasa yoga session, which disregarded the restorative phase of this session, the energy expenditure was $5.2 \pm 1.3 \mathrm{kcal} / \mathrm{min}(4.1 \pm 0.6 \mathrm{METS})$. While there are few studies to compare to in the literature, Hagins et al. ${ }^{22}$ reported that the mean energy cost during a 52 minute yoga session was $3.2 \pm 1.1$ $\mathrm{kcal} / \mathrm{min}$ (2.5 $\pm 0.8 \mathrm{METS})$, which appears to be lower than the energy expenditure observed in the current study. However, the specific style of yoga was not reported by Hagins et al. ${ }^{22}$ other than to describe this as including sun salutation, non-sun salutation standing poses, and sitting/lying poses. Thus, the difference in energy expenditure between the current study and the study reported by Hagins et al. ${ }^{22}$ may be a result of differences in the style of yoga and the poses that were included.

Carrol et al. ${ }^{23}$ published a scientific abstract and presented data at a professional conference on the energy cost of a Vinyasa style of yoga. It was reported that the energy cost was equivalent to 6.7 METS for a form of yoga that included both dynamic and isometric movements. ${ }^{23}$ This was higher than the approximate 4.0 MET level observed in the current study. Reasons for this difference in MET levels reported by Carrol et al. compared to the current study are not clear given the limited information provided in the published abstract. ${ }^{23}$ However, 
one could speculate that this may be a result of a different flow sequence used for the yoga session between the two studies. Moreover, Carrol et al. ${ }^{23}$ reported using a 15 minute yoga session, which may have allowed for a higher intensity, compared to the 45-60 minute session that was implemented in the current study. This may suggest the need for additional research to confirm the energy cost of different forms and styles of yoga.

The energy expenditure observed in the current study for Vinyasa yoga (approximately 4 METS) is of public health importance because this reflects moderate-intensity physical activity, typically defined as 3.0 to $<6.0$ METS. This intensity of physical activity has been shown to be important for impacting a variety of chronic health conditions that include cardiovascular disease, diabetes, cancer, and others ${ }^{2}$. In addition, yoga has been shown to have health benefits that include; decreased stress, ${ }^{10,11}$ mitigation of pain symptoms, ${ }^{12-14}$ improved mood and diminished depression, ${ }^{15,16}$ increased flexibility, ${ }^{17,18}$ and enhanced sleep. ${ }^{19,20}$ Yoga has also been shown to reduce resting blood pressure and heart rate ${ }^{21}$ and to potentially impact negative agerelated cardiovascular effects. ${ }^{22}$ Given these findings, Vinyasa yoga may be a viable form of physical activity to elicit significant health benefits.

A unique aspect of this study was that Vinyasa yoga was compared to walking performed at a self-selected brisk walking pace and to walking in which the heart rate was matched to the heart rate attained during the yoga session. This study found that energy expenditure in the Vinyasa yoga session was significantly lower than the energy expenditure in both the heart rate matched walk session and the self-selected walk session. One potential explanation for this is that the final 15 minutes of the Vinyasa yoga session reflects less intense restorative poses. Even after re-analyzing the data to only compare the initial 45 minutes from each of the experimental sessions, the energy expenditure in the Vinyasa yoga session remained significantly lower than 
the energy expenditure in the heart rate matched walk session. However, when the initial 45 minutes of Vinyasa yoga was compared to the initial 45 minutes of walking at a self-selected pace, there was no significant difference in energy expenditure. Given that participants were instructed to walk at a brisk, yet comfortable, pace during the self-selected walk session, these data may suggest aside from the restorative components of Vinyasa yoga, this form of physical activity can elicit an energy expenditure that is comparable to what an adult would attain during brisk walking.

Of interest is that the energy expenditure during Vinyasa yoga was significantly lower than the energy expenditure during walking when at the same intensity based on heart rate (heart rate matched walking) when the data were analyzed for both the 45 minute and 60 minute components of the yoga session. When compared to the walking session performed at the selfselected brisk walking pace, the heart rate response was significantly lower when walking compared to Vinyasa yoga, and this was accompanied with a higher energy expenditure in walking compared to yoga across the entire 60 minute session but not when only the initial 45 minutes were examined. The physiological rationale for the disassociation between heart rate and energy expenditure during Vinyasa yoga compared to walking is not able to be determined from this current study, which warrants further investigation. However, these data do suggest that one may not be able to regulate exercise intensity during Vinyasa yoga using heart rate in a manner that is similar to what would be done during activities such as brisk walking.

Given the potential limitation of using heart rate to regulate exercise intensity it may be necessary to apply other methods for this purpose. One alternative is the use of rating of perceived exertion $(\mathrm{RPE})^{24}$. In fact, RPE was assessed following each of the experimental exercise sessions in the current study. There was no significant difference between RPE reported 
at the end of the 60 minute sessions. Similar to what was observed with heart rate, energy expenditure was greater in the walking session compared to the yoga session. In contrast, the RPE was significantly higher in response to a 60 minute Vinyasa yoga session compared to the self-selected brisk walking session, yet the energy expenditure was significantly greater during walking compared to yoga. Thus, similar to heart rate, use of a standard RPE scale may not be appropriate for use to regulate exercise intensity during Vinyasa yoga. Rather, an exercise specific RPE scale may need to be developed for use during Vinyasa yoga to assist participants in regulating exercise intensity.

\subsection{STRENGTHS OF THE PRESENT STUDY}

The present study compared energy expenditure between walking and yoga, and it was designed to address limitations of previous research on the topic and to fill an important gap in the literature. There are a number of strengths to this study that include the following:

1. This study included a standardized Vinyasa yoga protocol with a video and a stylespecific sequence. This facilitated standardization across study participants and will allow for replication in future studies.

2. Participants received the experimental conditions in a randomized, crossover order. This may have minimized the influence of familiarization to the laboratory environment and equipment on the outcomes assessed in this study.

3. A familiarization session to the treadmill walking, yoga poses, and metabolic equipment was included prior to participation in the experimental sessions. This also 
allowed the investigator to confirm the ability of the participant to engage in the experimental procedures.

4. The participants were experienced in Vinyasa yoga but showed very diverse practices with almost all of them requiring modifications from the full poses (the modifications and frequency in which they were used can be found in Appendix F). Thus, given the diversity of yoga abilities across the participants in this study, the results may generalize to a broad population of individuals who practice Vinyasa yoga.

5. An equal number of men and women were recruited to participate in this study. This allowed for preliminary analysis of the data to examine whether the sex of the participants influenced the pattern of results across the experimental sessions.

\subsection{LIMITATIONS AND RECOMMENDATIONS FOR FUTURE RESEARCH}

Despite the numerous strengths of this study, there are also several limitations to this investigation that may have contributed to the interpretation of the observed outcomes. Therefore, these findings must be considered within the context of these limitations and future investigations should address the following:

1. This study was limited to individuals who are experienced in practicing Vinyasa yoga. Therefore, caution should be used when generalizing these findings to populations of individuals who do not practice yoga or practice a different style of yoga. 
2. The individuals who participated in the study were required to wear the metabolic mask and system during their yoga session. It is unknown if doing yoga while wearing this equipment may have influenced energy expenditure.

3. This study examined Vinyasa yoga. Therefore, it is unknown to what degree these findings can be generalized to other styles of yoga.

4. The RPE was collected at the completion of the exercise session and participants were asked to rate their exertion "across the entire session.” RPE assessed in this manner may not reflect the varying intensity in the exercise session. Future research should consider collecting RPE data at various points throughout the session and not only at the completion of the session.

5. The participants varied in their experience of practicing Vinyasa yoga. It is unknown if chronic training of this style of yoga changes energy expenditure. Future researcher might consider including participants who do not currently practice Vinyasa yoga and measure their energy expenditure both before and after chronic training in this style of yoga.

6. The participants were encouraged to take modifications as they would normally require in their yoga practice. The use of modifications may have implications on energy expenditure although it is unclear from this study which direction the modifications impact energy expenditure. This requires further investigation.

7. Because the exercise sessions were done in a controlled, laboratory setting, it is unclear whether these findings would directly apply to non-laboratory settings where participants may be cued differently during the yoga session, would be allowed to walk outside or would have other stimuli (such as music) that could influence their 
response to the activity sessions. Thus the exact data may not be able to be replicated outside of a controlled, laboratory setting.

\subsection{CONCLUSION}

Physical inactivity is a serious public health concern within the United States with estimates indicating that only approximately 5\% of adults in the United States engage in recommended levels to positively impact health. ${ }^{1}$ This is of significant concern because low levels of physical activity have been associated with increased mortality, with estimates of approximately 250,000 premature deaths annually attributed to insufficient physical activity. ${ }^{2}$ Additionally, physical activity has been recommended as an important lifestyle behavior to both prevent weight gain and to effectively treat overweight and obesity. ${ }^{7}$

There is wide support for inclusion of aerobic forms of physical activity to prevent weight gain, induce modest weight loss, and assist in prevention of weight regain following weight loss. ${ }^{7}$ Therefore, clinical treatment recommendations for obesity have typically encouraged inclusion of aerobic and/or resistance forms of physical activity. However, little is known about other forms of physical activity that may be effective for preventing weight gain or eliciting weight loss. Despite the rising popularity of yoga in the United States, The American College of Sports Medicine does not recommend that yoga be prescribed as a viable method for achieving moderate levels of physical activity minutes because very little research has been conducted examining the energy cost of yoga.

Prior to the current study, the metabolic cost of Vinyasa yoga had not been well examined. The energy expenditure observed in the current study for Vinyasa yoga 
(approximately 4 METS) is of public health importance because this reflects moderate-intensity physical activity, typically defined as 3.0 to $<6.0$ METS. This intensity of physical activity has been shown to be important for impacting a variety of chronic health conditions ${ }^{2}$. In addition, yoga has been shown to have numerous health benefits ${ }^{10-20}$. Yoga has also been shown to reduce resting blood pressure and heart rate $^{21}$ and to potentially impact negative age-related cardiovascular effects. ${ }^{22}$ Given these findings, Vinyasa yoga may be a viable form of physical activity to elicit significant health benefits. In addition to the potential energy cost of Vinyasa yoga that contributes to overall energy expenditure, there may be additional health benefits of this form of physical activity that can be especially beneficial within the context of improved weight control. Moreover, the current study found that Vinyasa yoga has a comparable metabolic impact to brisk walking. Thus, recommendations should be expanded to include this style of yoga to achieve public health recommendations for physical activity. This may provide justification to develop interventions to assist individuals to adopt the practice of Vinyasa yoga as a component of a comprehensive active lifestyle. 
APPENDIX A

PHONE SCREENING SCRIPT 


\section{Yoga Expenditure Study}

\section{Screening Script:}

1. Thank you for your interest in our program. My name is and I would briefly like to tell you about this research study.

2. Procedure for Describing the Study and Obtaining Verbal Consent to Conduct the Phone Screen: A description of the study will be read to the participants, and this description includes important component of the informed consent process (see attached script). Individuals who express an interest in participating in this study will be told the following to obtain verbal consent:

a. Investigators Component of Informed Consent: This study is being conducted by Sally A. Sherman, M.S., M.Ed., at the University of Pittsburgh.

b.

\section{Description Component of Informed Consent:}

The purpose of this study is to examine the calories burned in a yoga session compared to treadmill walking. We are interested in in recruiting 30 healthy, men and women, age 18-55, who are able to walk for exercise on a treadmill and have experience in yoga. If you are found to be initially eligible for the study after this phone screening, we will invite you to the Physical Activity and Weight Management Research Center at the University of Pittsburgh Oakland Campus for an orientation session where the full details of the study will be described to you, you will have a chance to ask questions, and if you are interested in participating, you will be asked to sign a consent document. Next, you will complete an assessment of your height, weight, percentage of fat in your body, and physical activity level. You will also be asked to perform brief bouts of yoga and treadmill walking to confirm that you are comfortable completing these physical activities. Following this, on 3 separate occasions you will be asked to come back to the Physical Activity and Weight Management Research Center to complete a 60-minute activity session. One session will be a 60-min yoga session, and the other 2 sessions will be 60-minute treadmill walking sessions similar to brisk walking. You can earn up to $\$ 200.00$ for your participation in this study.

To determine your eligibility, I will need to ask you a few questions about your demographic background and questions about your physical health and medical history. It will take approximately 5 minutes to ask you all of the questions. If we complete the interview, I will ask you for some specific information (i.e. complete name and phone number) to contact you regarding your further participation. If you are eligible, you will be scheduled to attend an orientation session where all of your questions will be answered in greater detail, and a consent document will be read and signed.

Your responses to these questions are confidential, and all information related to your health history and current behaviors that you are about to give me will all be destroyed after this interview if you are found to be ineligible. If an answer to a particular questions makes it clear that you are not eligible, I will stop the interview and not ask you any more questions.

Do you have any questions regarding the information I have provided you? 
Staff member will answer any questions prior to proceeding, if the individual would like to think about their participation prior to proceeding with the phone screen, they will be provided with the telephone number that they can call if they decide to participate in the future.

C. Voluntary Consent Component of Informed Consent:

Do I have your permission to ask these questions?

i. If "YES" indicate the participant's agreement with this statement on the top of the next page, sign your name and date the form, and then complete the phone screen. If "NO", thank the individual for calling and do not complete the phone screen. 


\section{Phone Screen Interview}

\section{Permission to Screen:}

The caller give verbal permission to conduct the Phone Screen:

YES

NO

Verbal Assent was given to:

Staff Member Signature

Date Verbal Assent was given:

Completed by the Principal Investigator:

Eligible based on telephone screening:

$\square$ Yes $\square$ No

If "No", list reason for ineligibility: 


\section{Screening Questions:}

1. What is your gender? Male Female (circle)

2. How old are you? [18-55]

3. What is your date of birth

4. Are you able to walk for exercise? (circle)

YES NO

5. Has a doctor or other medical persons ever told you that you have any of the following conditions?
a. Heart Disease
YES NO
(circle)
b. Angina
YES NO
c. Hypertension
YES NO
d. Stroke
YES NO
e. Heart attack
YES NO
f. Diabetes
YES NO
g. Cancer
YES NO

6. Are you currently taking any prescription medications?

\begin{tabular}{|l|l|}
\hline Medication & Used to treat? \\
\hline & \\
\hline & \\
\hline
\end{tabular}

7. Are you currently pregnant? (circle)

YES NO

8. Do you practice yoga?

YES NO (circle)

9. Are you comfortable walking on the treadmill?

YES NO (circle)

The following questions are from the Physical Activity Readiness Questionnaire (PAR-Q):

10. Has your doctor ever told you that you have a heart condition and YES NO that you should only do physical activity recommended by a doctor?

11. Do you feel pain in your chest when you do physical activity?

YES NO

12. In the past month, have you had chest pain when you were not

YES NO doing physical activity? 
13. Do you lose your balance because of dizziness or do you ever lose consciousness?

YES NO

14. Do you have a bone or joint problem (for example back, knee, or

YES NO hip) that could be made worse by a change in your physical activity?

15. Is your doctor currently prescribing drugs (for example water pills) YES NO for your blood pressure or heart condition?

16. Do you know of any other reason why you should not do physical YES NO activity?

\section{Final Steps:}

IF THE SUBJECT APPEARS TO BE:

- Ineligible based on the response to any question, stop the interview. Do not collect any additional information, and respond with the following:

"Based on the information you have provided, it appears that you are ineligible to participate at this time. All information collected will be destroyed at this point. Thank you for your time and have a nice day."

- Eligible at the end of the phone screening, respond with the following and complete the Contact Information below:

"Based on the information you have provided me, it appears that you are eligible to participate in the study. I will now schedule you for your orientation session (1 hour) where you will need to wear comfortable clothing and tennis shoes to walk on the treadmill in as well as clothes for a yoga practice. You will be permitted to change clothes during the orientation session in a private locker room."

\section{Contact Information}


*COMPLETE ONLY IF THE RESPONDANT APPEARS TO BE ELIGIBLE FOR PARTICIPATION

IN THIS STUDY*

\section{Contact Information:}

First Name: Last Name:

Phone Number:

Home

Work

Cell

Home

Work

Cell

Home

Work

Cell

\section{OFFICE USE ONLY:}

Eligible:

Invited to Orientation:

Orientation Date:
YES

YES
NO

NO 
APPENDIX B

DEMOGRAPHICS AND MEDICAL HISTORY QUESTIONNAIRE 


\begin{tabular}{|c|c|}
\hline \multicolumn{2}{|l|}{ Office Use Only } \\
\hline Subject ID \#: & Assessment \#: \\
\hline
\end{tabular}

\section{DEMOGRAPHICS}

1. Are you of Hispanic or Latino origin?

$\square$ Yes

$\square_{\mathrm{No}}$

2. Which race best describes you? (Check all that apply)

NIH Census labels

$\square$ White or Caucasian

$\square$ Black or African American

$\square$ American Indian/Native American

$\square$ Native Hawaiian or other Pacific Islander

$\square$ Asian

$\square$ Other:

3. What is your gender? (Check one)

$\square$ Male

$\square$ Female

4. Date of birth:

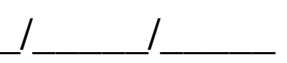

5. What is the highest grade in school you have finished? (Check one)

$\square \quad$ Did not finish elementary school

$\square \quad$ Finished middle school (8th grade)

$\square \quad$ Finished some high school 

$\square \quad$ High school graduate or G.E.D
$\square \quad$ Vocational or training school after high school
$\square$ Some College or Associate degree
$\square \quad$ College graduate or Baccalaureate Degree
$\square \quad$ Masters or Doctoral Degree (PhD, MD, JD, etc)

6. How many children under the age of 18 live in your home?

7. How many adults (age 18 or older) live in your home (include yourself)?

8. What is your current marital status? (Check One)

$\square \quad$ Married
$\square \quad$ Separated
$\square \quad$ Divorced
$\square \quad$ Widowed
$\square \quad$ Single / Not Married

9. Which of these categories best describe your income (not the income of your household, but your own income) for the past 12 months? This should include income (before taxes) from all sources, wages, veteran's benefits, help from relatives, rent from properties and so on.

$\square \quad$ Less than $\$ 5,000$
$\square \quad \$ 5,000$ through $\$ 11,999$
$\square \quad \$ 12,000$ through $\$ 15,999$
$\square \quad \$ 16,000$ through $\$ 24,999$
$\square \quad \$ 25,000$ through $\$ 34,999$
$\square \quad \$ 35,000$ through $\$ 49,999$ 

$\square \quad \$ 50,000$ through $\$ 74,999$
$\square \quad \$ 75,000$ through $\$ 99,999$
$\square \$ 100,000$ and greater
$\square \quad$ Don't know

\section{SMOKING}

10. Do you currently use chewing tobacco, snuff, snus, pipes, cigars or any other tobacco product other than cigarettes?
$\square$ Yes
$\square \quad$ No

11. Have you smoked at least 100 cigarettes in your entire life? NOTE: $\mathbf{5}$ packs $=\mathbf{1 0 0}$ cigarettes
$\square \quad$ Yes
$\square \quad$ No

12. Do you now smoke cigarettes every day, some days, or not at all?
$\square \quad$ Every day
$\square \quad$ Some days
$\square \quad$ Not at all If 'Not at all', skip to question \#14 of this section

13. On average, how many cigarettes do you smoke each day?

$\square \quad$ I did not smoke cigarettes during the past 30 days

$\square \quad 1$ cigarette or less per day

$\square \quad 2$ to 5 cigarettes per day 

$\square \quad 6$ to 10 cigarettes per day
$\square \quad 11$ to 20 cigarettes per day
$\square \quad$ More than 20 cigarettes per day

14. During the past 12 months, have you stopped smoking for one day or longer because you were trying to quit smoking?
$\square \quad$ Yes
$\square \quad$ No If 'No', skip to Question 16.

15. How long has it been since you last smoked cigarettes regularly?

$\square \quad$ Within the past month (less than 1 month ago)

$\square \quad$ Within the past 3 months (1 month but less than 3 months ago)

$\square \quad$ Within the past 6 months (3 months but less than 6 months ago)

$\square \quad$ Within the past year (6 months but less than 1 year ago)

$\square \quad$ Within the past 5 years (1 year but less than 5 years ago)

$\square \quad$ Within the past 10 years (5 years but less than 10 years ago)

$\square \quad 10$ years or more

\section{ALCOHOL}

16. During the past 30 days, have you had at least one drink of any alcoholic beverage such as beer, wine, a malt beverage or liquor? NOTE: One drink is equivalent to a 12-ounce beer, a 5-ounce glass of wine, or a drink with one shot of liquor.

$\square \quad$ Yes

$\square \quad$ No If 'No', then STOP and do not answer Questions 17, 18, 19

17. During the past 30 days, how many days did you have at least one drink of any alcoholic beverage?

Days in past 30 days 
18. During the past 30 days, on the days when you drank, about how many drinks did you drink on average? NOTE: A 40-ounce beer would count as 3 drinks, or a cocktail drink with 2 shots would count as 2 drinks.

Number of drinks per day

19. Considering all types of alcoholic beverages, how many times during the past 30 days did you have 4 or more drinks (for women) or 5 or more drinks (for males)

Number of times

$\square \quad$ None

20. Do you have or have you ever had any of the following medical conditions?

$\begin{array}{ll}\text { Approximate } & \text { Describe the } \\ \text { Date of } & \text { Problem } \\ \text { Diagnosis } & \end{array}$
a. Heart Attack
$\square$ yes $\square$ no
b. Angina (chest pain on exertion)
$\square$ yes $\square$ no
c. Irregular Heart Problems
$\square$ yes $\square$ no
d. Other Heart Problems
$\square$ yes $\square$ no
e. Stroke
f. Fainting Spells
g. High Blood Pressure
$\square$ yes $\square$ no
h. High Cholesterol
$\square$ yes $\square$ no
i. Thyroid Problems
$\square$ yes $\square$ no
$\square$ yes $\square$ no
j. Cancer
$\square$ yes $\square$ no
k. Kidney Problems
$\square$ yes $\square$ no
I. Liver Problems
$\square$ yes $\square$ no
$\square$ yes $\square$ no
m. Gout
$\square$ yes $\square$ no
n. Diabetes
o. Emotional/Psychiatric Problems
$\square$ yes $\square$ no
p. Drug/Alcohol Problems
$\square$ yes $\square$ no
$\square$ yes $\square$ no

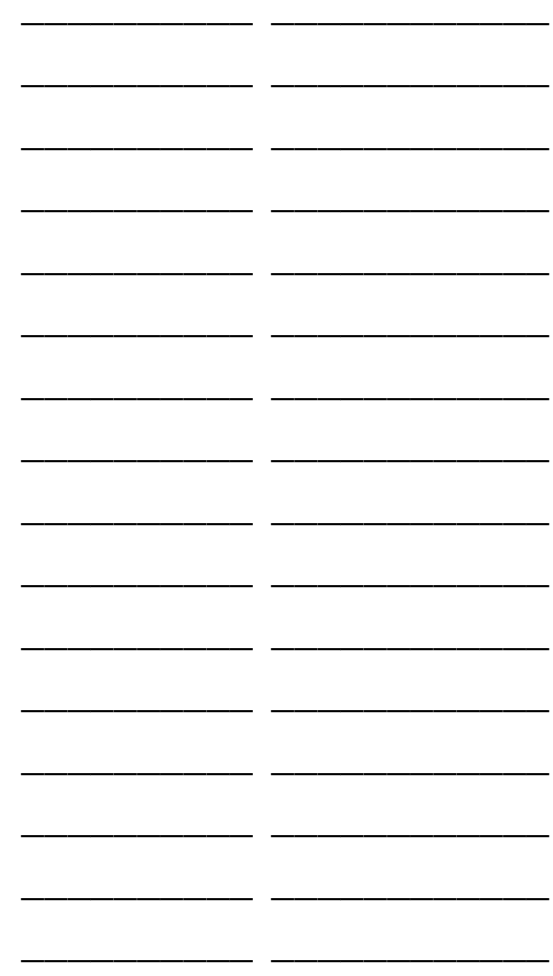

21. Do you have any medical problems that would prevent you from participating in a regular walking program? $\square$ yes $\square$ no

If yes, please describe the problem: 
22. Do you have to sleep with extra pillows or have to sit up in the middle of the night because of shortness of breath? $\square$ yes $\square$ no

23. Please list all medications that you are currently taking on a regular basis (make sure to indicate if you are taking medication for high blood pressure or cholesterol):

MEDICATION

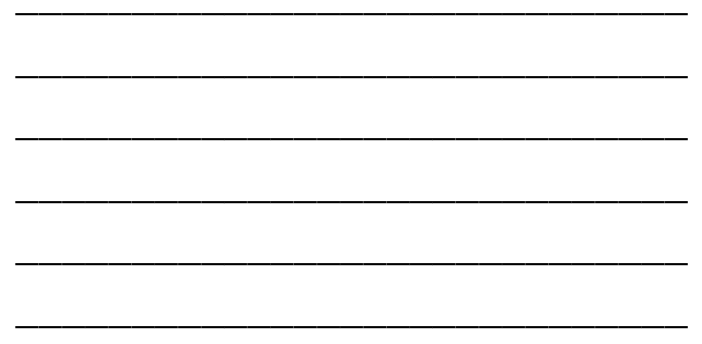

REASON FOR TAKING 
APPENDIX C

\section{ORIENTATION SCRIPT AND CHECK LIST}




\section{Orientation Session}

\section{Familiarization Trials}

1. First, review study protocol and obtain informed consent.

2. Fit subject for metabolic equipment

TREADMILL TRIAL

3. Put subject on treadmill at $2.0 \mathrm{mph}$ and ask them to walk. Increase treadmill every 30 seconds in $0.5 \mathrm{mph}$ increments until subject signals that they are at their desired pace for comfort

4. Walk for approximately 3 minutes then bring subject back down to $0.0 \mathrm{mph}$

5. Ask subject to do the following poses while wearing the metabolic facemask:
a. Child's pose
b. Downward Facing Dog
c. High/Low push up
d. Up Dog
e. Downward Facing Dog
f. Warrior 1
g. Eagle (showing modification of arms to accommodate equipment)
h. Locust (showing gentle lower to floor to accommodate equipment)
i. Frog

6. Ask subject if they have any questions or need clarification 


\section{APPENDIX D}

DATA COLLECTION SHEETS 


\section{Heart Rate Matched Treadmill Protocol}

ID\#:

Date:

Height: \#1

cm. \#2

cm. Weight: \#1

kg. \#2

kg. Gender: Male Female

Date of Birth:

Age:

BIA Resistance:

Reactance:

Temperature:

degrees C Barometric Pressure:

hPa Relative Humidity: $\%$

Set treadmill to speed of $2.0 \mathrm{mph}$ and $0 \%$ incline and instruct subject to begin walking.

Every 30 seconds, increase the speed of the treadmill with by $0.2 \mathrm{mph}$ until the subject achieves the target $\mathrm{HF}+/-5$ bpm. After the initial 5 minutes, make adjustments to the range throughout the 15 minute period. Repeat protocol each 15 minutes to adjust for the change in HR across the 60 minutes.

\begin{tabular}{|c|c|c|c|c|c|}
\hline Time (minutes) & Speed (mph) & \%Grade & Heart Rate & $\begin{array}{c}\text { Average } \\
\text { Heart Rate }\end{array}$ & $\begin{array}{c}\text { Target Average Heart } \\
\text { Rate from Yoga } \\
\text { Session }\end{array}$ \\
\hline 0:00-1:00 & \multicolumn{2}{|c|}{ Seated } & & & \\
\hline 1:01-2:00 & \multicolumn{2}{|c|}{ Seated } & & & \\
\hline 2:01-3:00 & \multicolumn{2}{|c|}{ Seated } & & & \\
\hline 3:01-4:00 & \multicolumn{2}{|c|}{ Seated } & & & \\
\hline 4:01-5:00 & \multicolumn{2}{|c|}{ Seated } & & & \\
\hline \multirow{2}{*}{\multicolumn{6}{|c|}{ 0:00-1:00 }} \\
\hline & & & & & \\
\hline \multicolumn{6}{|l|}{ 1:01-2:00 } \\
\hline \multicolumn{6}{|l|}{ 2:01-3:00 } \\
\hline \multicolumn{6}{|l|}{ 3:01-4:00 } \\
\hline \multicolumn{6}{|l|}{ 4:01-5:00 } \\
\hline \multicolumn{6}{|l|}{ 5:01-6:00 } \\
\hline \multicolumn{6}{|l|}{ 6:01-7:00 } \\
\hline \multicolumn{6}{|l|}{ 7:01-8:00 } \\
\hline \multirow{2}{*}{\multicolumn{6}{|c|}{$\begin{array}{c}8: 01-9: 00 \\
9: 01-10: 00\end{array}$}} \\
\hline & & & & & \\
\hline \multicolumn{6}{|l|}{$10: 00-11: 00$} \\
\hline \multicolumn{6}{|l|}{ 11:01-12:00 } \\
\hline \multicolumn{6}{|l|}{ 12:01-13:00 } \\
\hline \multicolumn{6}{|l|}{ 13:01-14:00 } \\
\hline \multicolumn{6}{|l|}{ 14:01-15:00 } \\
\hline \multicolumn{6}{|l|}{ 15:01-16:00 } \\
\hline \multicolumn{6}{|l|}{$16: 01-17: 00$} \\
\hline \multicolumn{6}{|l|}{$17: 01-18: 00$} \\
\hline \multirow{2}{*}{\multicolumn{6}{|c|}{ 18:01-19:00 }} \\
\hline \multicolumn{4}{|l|}{ 19:01-20:00 } & & \\
\hline \multicolumn{6}{|l|}{ 20:00-21:00 } \\
\hline \multicolumn{6}{|l|}{ 21:01-22:00 } \\
\hline \multirow{2}{*}{\multicolumn{6}{|c|}{$\begin{array}{l}22: 01-23: 00 \\
23: 01-24: 00\end{array}$}} \\
\hline & & & & & \\
\hline \multicolumn{6}{|l|}{$\begin{array}{l}23: 01-24: 00 \\
24: 01-25: 00\end{array}$} \\
\hline \multicolumn{4}{|l|}{$\begin{array}{l}24: 01-25: 00 \\
25: 01-26: 00\end{array}$} & & \\
\hline $26: 01-27: 00$ & & & & & \\
\hline 27:01-28:00 & & & & & \\
\hline
\end{tabular}




\begin{tabular}{|c|c|c|c|c|c|}
\hline $\begin{array}{l}28: 01-29: 00 \\
29: 01-30: 00\end{array}$ & & & & \multirow{7}{*}{$\begin{array}{c}\text { Average } \\
\text { Heart Rate }\end{array}$} & \multirow{17}{*}{$\begin{array}{c}\text { Target Average Heart } \\
\text { Rate from Yoga } \\
\text { Session }\end{array}$} \\
\hline Time (minutes) & Speed (mph) & \%Grade & Heart Rate & & \\
\hline \multicolumn{4}{|l|}{ 30:00-31:00 } & & \\
\hline \multicolumn{4}{|l|}{ 31:01-32:00 } & & \\
\hline \multicolumn{4}{|l|}{ 32:01-33:00 } & & \\
\hline \multicolumn{4}{|l|}{ 33:01-34:00 } & & \\
\hline \multirow{2}{*}{\multicolumn{4}{|c|}{ 34:01-35:00 }} & & \\
\hline \multicolumn{3}{|l|}{ 35:01-36:00 } & & & \\
\hline \multicolumn{5}{|l|}{ 36:01-37:00 } & \\
\hline \multicolumn{5}{|l|}{ 37:01-38:00 } & \\
\hline \multicolumn{5}{|l|}{$38: 01-39: 00$} & \\
\hline \multicolumn{5}{|l|}{ 39:01-40:00 } & \\
\hline \multicolumn{5}{|l|}{ 40:00-41:00 } & \\
\hline \multicolumn{5}{|l|}{ 41:01-42:00 } & \\
\hline \multicolumn{5}{|l|}{ 42:01-43:00 } & \\
\hline \multicolumn{5}{|l|}{ 43:01-44:00 } & \\
\hline \multicolumn{5}{|l|}{ 44:01-45:00 } & \\
\hline \multicolumn{5}{|l|}{ 45:01-46:00 } & \\
\hline \multicolumn{5}{|l|}{$46: 01-47: 00$} & \\
\hline \multicolumn{5}{|l|}{ 47:01-48:00 } & \\
\hline \multicolumn{5}{|l|}{ 48:01-49:00 } & \\
\hline \multicolumn{5}{|l|}{ 49:01-50:00 } & \\
\hline \multicolumn{5}{|l|}{$50: 00-51: 00$} & \\
\hline & \\
\hline \multicolumn{5}{|l|}{$\begin{array}{l}\text { 51:01-52:00 } \\
52: 01-53: 00\end{array}$} & \\
\hline \multicolumn{5}{|l|}{$\begin{array}{c}52: 01-53: 00 \\
53: 01-54: 00\end{array}$} & \\
\hline \multicolumn{5}{|l|}{$\begin{array}{c}\text { 53:01-54:00 } \\
\text { 54:01-55:00 }\end{array}$} & \\
\hline 55:01-56:00 & & & & & \\
\hline 56:01-57:00 & & & & & \\
\hline 57:01-58:00 & & & & & \\
\hline 58:01-59:00 & & & & & \\
\hline 59:01-60:00 & & & & & \\
\hline $0: 00-1: 00$ & Seates & very & & & \\
\hline 1:01-2:00 & Seates & very & & & \\
\hline 2:01-3:00 & Seate & very & & & \\
\hline 3:01-4:00 & Seater & very & & & \\
\hline 4:01-5:00 & Seates & very & & & \\
\hline & & & & & \\
\hline
\end{tabular}

Across the entire exercise session, on a scale of 6-20 with 20 being the hardest, how would you rate how hard you were working? (SHOW BORG SCALE)

Rating of Perceived Exertion (taken at conclusion of 60 minute session):

\section{Comments:}




\section{Self-Selected Walking Pace Treadmill Protocol}

ID\#:

Date:

Height: \#1

cm. \#2

cm. Weight: \#1

kg. \#2

kg. Gender: Male Female

Date of Birth:

Age:

BIA Resistance:

Reactance:

Temperature: degree C Barometric Pressure:

hPa Relative Humidity: $\%$

Set treadmill to speed of $1.0 \mathrm{mph}$ and $0 \%$ incline and instruct subject to begin walking.

During the initial 5 minutes, increase the speed in $0.5 \mathrm{mph}$ increments until the subject signals that they have reached their "comfortable self-selected brisk walking pace."

Ask the subject at 5 minute intervals throughout the entire exercise session if they wish to increase or decrease their speed for their comfort. These adjustments can made in $0.5 \mathrm{mph}$ increments.

\begin{tabular}{|c|c|c|c|c|}
\hline Time (minutes) & Speed (mph) & \% Grade & Heart Rate & $\begin{array}{c}\text { Average } \\
\text { Heart Rate }\end{array}$ \\
\hline $0: 00-1: 00$ & \multicolumn{2}{|c|}{ Seated } & & \\
\hline 1:01-2:00 & \multicolumn{2}{|c|}{ Seated } & & \\
\hline 2:01-3:00 & \multicolumn{2}{|c|}{ Seated } & & \\
\hline 3:01-4:00 & \multirow{2}{*}{\multicolumn{2}{|c|}{$\begin{array}{l}\text { Seated } \\
\text { Seated }\end{array}$}} & & \\
\hline 4:01-5:00 & & & & \\
\hline \multirow{2}{*}{\multicolumn{5}{|c|}{$0: 00-1: 00$}} \\
\hline & & & & \\
\hline \multicolumn{5}{|l|}{$\frac{0: 00-1: 00}{1: 01-2: 00}$} \\
\hline \multicolumn{5}{|l|}{ 2:01-3:00 } \\
\hline \multicolumn{5}{|l|}{$3: 01-4: 00$} \\
\hline \multicolumn{5}{|l|}{ 4:01-5:00 } \\
\hline \multicolumn{5}{|l|}{ 5:01-6:00 } \\
\hline \multirow{2}{*}{\multicolumn{5}{|c|}{ 6:01-7:00 }} \\
\hline \multirow{2}{*}{\multicolumn{5}{|c|}{$\begin{array}{l}7: 01-8: 00 \\
8: 01-9: 00\end{array}$}} \\
\hline & & & & \\
\hline \multicolumn{5}{|l|}{ 9:01-10:00:00 } \\
\hline \multicolumn{5}{|l|}{ 10:00-11:00 } \\
\hline \multicolumn{5}{|l|}{ 11:01-12:00 } \\
\hline \multicolumn{5}{|l|}{ 12:01-13:00 } \\
\hline \multicolumn{5}{|l|}{ 13:01-14:00 } \\
\hline \multicolumn{5}{|l|}{ 14:01-15:00 } \\
\hline \multicolumn{5}{|l|}{ 15:01-16:00 } \\
\hline \multicolumn{5}{|l|}{ 16:01-17:00 } \\
\hline \multicolumn{5}{|l|}{ 17:01-18:00 } \\
\hline \multicolumn{5}{|l|}{ 18:01-19:00 } \\
\hline \multicolumn{5}{|l|}{ 19:01-20:00 } \\
\hline \multicolumn{5}{|l|}{ 20:00-21:00 } \\
\hline \multicolumn{5}{|l|}{ 21:01-22:00 } \\
\hline \multicolumn{5}{|l|}{ 22:01-23:00 } \\
\hline \multirow{2}{*}{\multicolumn{5}{|c|}{$\begin{array}{l}23: 01-24: 00 \\
24: 01-25: 00\end{array}$}} \\
\hline & & & & \\
\hline 25:01-26:00 & & & & \\
\hline 26:01-27:00 & & & & \\
\hline $27: 01-28: 00$ & & & & \\
\hline
\end{tabular}




\begin{tabular}{|c|c|c|c|c|}
\hline 28:01-29:00 & \multirow[b]{4}{*}{ Speed (mph) } & \multirow[b]{4}{*}{ \% Grade } & \multirow[b]{4}{*}{ Heart Rate } & \multirow{8}{*}{$\begin{array}{c}\text { Average } \\
\text { Heart Rate }\end{array}$} \\
\hline 29:01-30:00 & & & & \\
\hline $30: 01-31: 00$ & & & & \\
\hline Time (minutes) & & & & \\
\hline 31:01-32:00 & & & & \\
\hline 32:01-33:00 & & & & \\
\hline $33: 01-34: 00$ & & & & \\
\hline $34: 01-35: 00$ & & & & \\
\hline $35: 01-36: 00$ & & & & \\
\hline $36: 01-37: 00$ & & & & \\
\hline $37: 01-38: 00$ & & & & \\
\hline 38:01-39:00 & & & & \\
\hline 39:01-40:00 & & & & \\
\hline $40: 00-41: 00$ & & & & \\
\hline $41: 01-42: 00$ & & & & \\
\hline 42:01-43:00 & & & & \\
\hline $43: 01-44: 00$ & & & & \\
\hline $44: 01-45: 00$ & & & & \\
\hline $45: 01-46: 00$ & & & & \\
\hline $46: 01-47: 00$ & & & & \\
\hline 47:01-48:00 & & & & \\
\hline 48:01-49:00 & & & & \\
\hline 49:01-50:00 & & & & \\
\hline 50:00-51:00 & & & & \\
\hline 51:01-52:00 & & & & \\
\hline 52:01-53:00 & & & & \\
\hline 53:01-54:00 & & & & \\
\hline 54:01-55:00 & & & & \\
\hline 55:01-56:00 & & & & \\
\hline $56: 01-57: 00$ & & & & \\
\hline 57:01-58:00 & & & & \\
\hline 58:01-59:00 & & & & \\
\hline 59:01-60:00 & & & & \\
\hline 0:00-1:00 & Seated & very & & \\
\hline 1:01-2:00 & Seated & very & & \\
\hline 2:01-3:00 & Seated & very & & \\
\hline 3:01-4:00 & Seated & very & & \\
\hline 4:01-5:00 & Seated & very & & \\
\hline & & & & \\
\hline
\end{tabular}

Across the entire exercise session, on a scale of 6-20 with 20 being the hardest, how would you rate how hard you were working? (SHOW BORG SCALE)

Rating of Perceived Exertion (taken at conclusion of 60 minute session):

\section{Comments:}




\section{Yoga Protocol}

ID\#:

Date:

Height: \#1 cm. \#2 cm. Weight: \#1 kg. \#2 kg. Gender: Male Female

Date of Birth: Age:

BIA Resistance:

Reactance:

Temperature: degrees C Barometric Pressure:

hPa $\quad$ Relative Humidity:

$\%$

\begin{tabular}{|c|c|c|c|c|c|c|c|c|c|c|c|}
\hline \multirow{2}{*}{$\begin{array}{c}\text { Time (minutes) } \\
0: 00-1: 00\end{array}$} & \multirow{2}{*}{$\begin{array}{c}\text { Activity } \\
\text { Seated }\end{array}$} & \multirow[t]{2}{*}{ Heart Rate (bpm) } & & \multicolumn{3}{|c|}{ Asana 1} & \multicolumn{2}{|l|}{ Asana 2} & \multicolumn{3}{|c|}{ Asana 3} \\
\hline & & & & & & & & & & & \\
\hline $1: 01-2: 00$ & Seated & & & & & & & & & & \\
\hline $2: 01-3: 00$ & Seated & & & & & & & & & & \\
\hline $3: 01-4: 00$ & Seated & & & & & & & & & & \\
\hline \multirow[t]{2}{*}{ 4:01-5:00 } & Seated & & & & & & & & & & \\
\hline & & & $\begin{array}{c}\text { Average Heart } \\
\text { Rate for Use in } \\
\text { Heart Rate } \\
\text { Matched Trial }\end{array}$ & & & & & & & & \\
\hline $0: 00-1: 00$ & Yoga & & & Childs pose & M1 & M2 & \multicolumn{3}{|c|}{ Down dog } & M1 & M2 \\
\hline 1:01-2:00 & Yoga & & & $\begin{array}{c}3 \text { legged dog } \\
\mathrm{R}\end{array}$ & M1 & M2 & \multicolumn{3}{|c|}{3 legged dog $L$} & M1 & M2 \\
\hline $2: 01-3: 00$ & Yoga & & & Ragdoll & M1 & M2 & Mountain & M2 & $3 \mathrm{Oms}$ & M1 & $\mathrm{M} 2$ \\
\hline 3:01-4:00 & Yoga & & & \multicolumn{6}{|c|}{ Sun A 1} & M1 & $\mathrm{M} 2$ \\
\hline $4: 01-5: 00$ & Yoga & & & \multicolumn{6}{|c|}{ Sun A 2} & M1 & M2 \\
\hline $5: 01-6: 00$ & Yoga & & & Sun A 3 & M1 & M2 & \multirow{2}{*}{\multicolumn{3}{|c|}{ Sun A 4}} & M1 & M2 \\
\hline $6: 01-7: 00$ & Yoga & & & & & & & & & M1 & M2 \\
\hline $7: 01-8: 00$ & Yoga & & & & & & Sun B 1 & & & M1 & $\mathrm{M} 2$ \\
\hline $8: 01-9: 00$ & Yoga & & & \multicolumn{6}{|c|}{ Sun B 1} & M1 & M2 \\
\hline 9:01-10:00 & Yoga & & & \multicolumn{6}{|c|}{ Sun B 2} & M1 & M2 \\
\hline $10: 00-11: 00$ & Yoga & & & \multicolumn{6}{|c|}{ Sun B 3} & M1 & $\mathrm{M} 2$ \\
\hline $11: 01-12: 00$ & Yoga & & & \multicolumn{6}{|c|}{ Sun B 3} & M1 & $\mathrm{M} 2$ \\
\hline 12:01-13:00 & Yoga & & & \multicolumn{6}{|c|}{ Sun B 4} & M1 & $\mathrm{M} 2$ \\
\hline 13:01-14:00 & Yoga & & & \multicolumn{6}{|c|}{ Sun B 5} & M1 & M2 \\
\hline 14:01-15:00 & Yoga & & & Flip dog $\mathrm{R}$ & M1 & M2 & \multicolumn{3}{|c|}{ Side plank R } & M1 & M2 \\
\hline 15:01-16:00 & Yoga & & & $\begin{array}{l}\text { Crescent } \\
\text { lunge } \mathrm{R}\end{array}$ & M1 & M2 & \multicolumn{3}{|c|}{ Crescent twist R } & M1 & M2 \\
\hline $16: 01-17: 00$ & Yoga & & & Warrior II & M1 & M2 & \multicolumn{3}{|c|}{ Extended side angle } & M1 & M2 \\
\hline $17: 01-18: 00$ & Yoga & & & Flip dog L & M1 & M2 & \multicolumn{3}{|c|}{ Side plank L } & M1 & M2 \\
\hline
\end{tabular}




\begin{tabular}{|c|c|c|c|c|c|c|c|c|c|}
\hline 18:01-19:00 & Yoga & $\begin{array}{l}\text { Crescent } \\
\text { lunge L }\end{array}$ & M1 & M2 & \multicolumn{3}{|c|}{ Crescent twist L } & M1 & M2 \\
\hline 19:01-20:00 & Yoga & Warrior II & M1 & M2 & \multicolumn{3}{|c|}{ Extended side angle } & M1 & M2 \\
\hline 20:00-21:00 & Yoga & Chair & M1 & M2 & \multicolumn{3}{|c|}{ Chair twist } & M1 & M2 \\
\hline 21:01-22:00 & Yoga & Forward fold & M1 & M2 & \multicolumn{3}{|c|}{ Crow } & M1 & M2 \\
\hline 22:01-23:00 & Yoga & \multicolumn{6}{|c|}{ Chair } & M1 & M2 \\
\hline 23:01-24:00 & Yoga & Chair twist & M1 & M2 & \multicolumn{3}{|c|}{ Forward fold } & M1 & M2 \\
\hline 24:01-25:00 & Yoga & \multicolumn{6}{|c|}{ Crow } & M1 & M2 \\
\hline 25:01-26:00 & Yoga & Eagle R & M1 & M2 & Eagle L & M2 & Eagle R & M1 & M2 \\
\hline 26:01-27:00 & Yoga & Eagle L & M1 & M2 & \multicolumn{3}{|c|}{ Leg raise $\mathrm{R}$} & M1 & M2 \\
\hline 27:01-28:00 & Yoga & Airplane R & M1 & M2 & \multicolumn{3}{|c|}{ Half moon $\mathrm{R}$} & M1 & M2 \\
\hline 28:01-29:00 & Yoga & Leg raise $\mathrm{L}$ & M1 & M2 & \multicolumn{3}{|c|}{ Airplane L } & M1 & M2 \\
\hline 29:01-30:00 & Yoga & Half moon L & M1 & M2 & \multicolumn{3}{|c|}{ Dancer R } & M1 & M2 \\
\hline 30:00-31:00 & Yoga & Dancer L & M1 & M2 & Dancer R & M2 & Dancer L & M1 & M2 \\
\hline 31:01-32:00 & Yoga & Tree R & M1 & M2 & \multicolumn{3}{|c|}{ Tree L } & M1 & M2 \\
\hline 32:01-33:00 & Yoga & Warrior II & M1 & M2 & \multicolumn{3}{|c|}{ Triangle R } & M1 & M2 \\
\hline 33:01-34:00 & Yoga & $\begin{array}{c}\text { Wide leg } \\
\text { fold }\end{array}$ & M1 & M2 & \multicolumn{3}{|c|}{ Pyramid R } & M1 & M2 \\
\hline 34:01-35:00 & Yoga & $\begin{array}{c}\text { Twist } \\
\text { triangle R }\end{array}$ & M1 & M2 & \multicolumn{3}{|c|}{ Warrior II } & M1 & M2 \\
\hline 35:01-36:00 & Yoga & Triangle R & M1 & M2 & \multicolumn{3}{|c|}{ Wide leg fold } & M1 & M2 \\
\hline 36:01-37:00 & Yoga & Pyramid L & M1 & M2 & \multicolumn{3}{|c|}{ Twist triangle L } & M1 & M2 \\
\hline 37:01-38:00 & Yoga & Locust 1 & M1 & M2 & \multicolumn{3}{|c|}{ Locust 2} & M1 & M2 \\
\hline 38:01-39:00 & Yoga & Bow 1 & M1 & M2 & \multicolumn{3}{|c|}{ Bow 2} & M1 & M2 \\
\hline 39:01-40:00 & Yoga & Camel 1 & M1 & M2 & \multicolumn{3}{|c|}{ Camel 2} & M1 & M2 \\
\hline 40:00-41:00 & Yoga & Bridge & M1 & M2 & \multicolumn{3}{|c|}{ Wheel 1} & M1 & M2 \\
\hline 41:01-42:00 & Yoga & Wheel 2 & M1 & M2 & \multicolumn{3}{|c|}{ Wheel 3} & M1 & M2 \\
\hline 42:01-43:00 & Yoga & Wheel 4 & M1 & M2 & \multicolumn{3}{|c|}{ Wheel 5} & M1 & M2 \\
\hline 43:01-44:00 & Yoga & Wheel 6 & M1 & M2 & \multicolumn{3}{|c|}{ Supine butterfly } & M1 & M2 \\
\hline 44:01-45:00 & Yoga & Happy baby & M1 & M2 & \multicolumn{3}{|c|}{ Boat } & M1 & M2 \\
\hline 45:01-46:00 & Yoga & $\begin{array}{c}\text { Half pigeon } \\
\text { R }\end{array}$ & M1 & M2 & \multicolumn{3}{|c|}{ Double pigeon $\mathrm{R}$} & M1 & M2 \\
\hline 46:01-47:00 & Yoga & & & & Half pigeon $\mathrm{R}$ & & & M1 & M2 \\
\hline 47:01-48:00 & Yoga & & & & Double pigeon $\mathrm{L}$ & & & M1 & M2 \\
\hline 48:01-49:00 & Yoga & & & & Frog & & & M1 & M2 \\
\hline 49:01-50:00 & Yoga & & & & Single leg R & & & M1 & M2 \\
\hline 50:00-51:00 & Yoga & & & & Single leg $\mathrm{L}$ & & & M1 & M2 \\
\hline 51:01-52:00 & Yoga & $\begin{array}{c}\text { Double leg } \\
\text { ext }\end{array}$ & M1 & M2 & Table & & & M1 & M2 \\
\hline 52:01-53:00 & Yoga & & & & Fish & & & M1 & M2 \\
\hline 53:01-54:00 & Yoga & & & & Shoulder stand & & & M1 & M2 \\
\hline
\end{tabular}




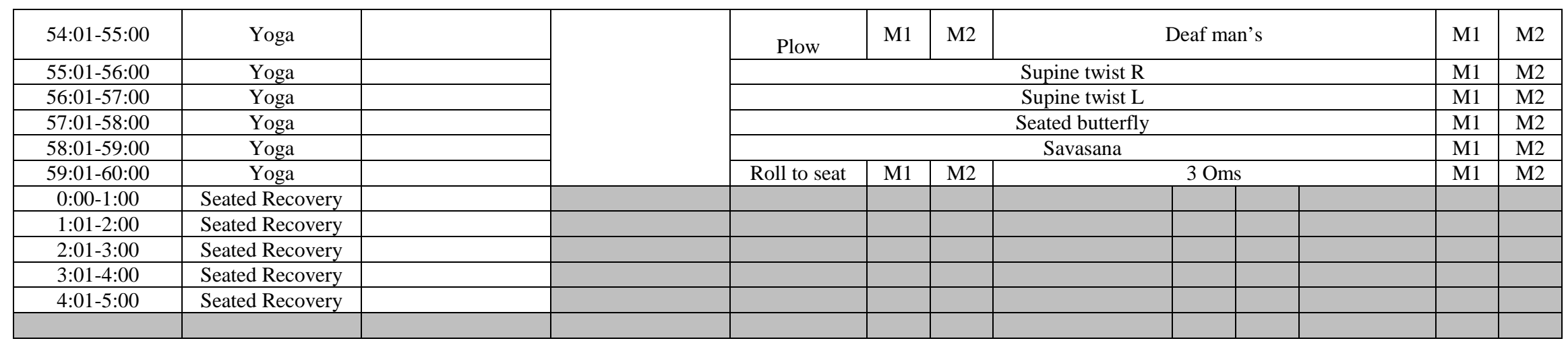

Across the entire yoga session, on a scale of 6-20 with 20 being the hardest, how would you rate how hard you were working? (SHOW BORG SCALE)

Rating of Perceived Exertion (taken at conclusion of 60 minute session):

Comments 
APPENDIX E

YOGA PROTOCOL 


\section{Vinyasa Yoga Protocol}

\section{5 breaths $=20$ seconds}

10 breaths each

Child's pose

Downward facing dog

5 breaths each

Right leg bend and open

Left leg bend and open

5 breaths each

Ragdoll

Roll to Mountain pose

Hands to heart, 3 Oms

1 breath per pose

Sun Salutation A x 5

Sun Salutation B $\times 5$

(for the first Sun Salutation $B$, hold each

pose 5 breaths)

5 breaths per pose

Flip dog right

Side plank right

(vinyasa to downward facing dog)

Crescent lunge right

Crescent lunge twist right

Warrior 2

Extended side angle right

(vinyasa and repeat on left side)

5 breaths per pose

Thunderbolt chair

Thunderbolt chair twist right

10 breaths each

Fingers to toes forward fold
5 breaths each

Crow

(vinyasa to downward facing dog)

Downward facing dog

Thunderbolt chair

Thunderbolt chair twist left

10 breaths each

Palms to toes forward fold

5 breaths each

Crow

(vinyasa to downward facing dog)

5 breaths per pose

Eagle (right, left, right left)

Standing leg raise right

Airplane

Half moon

Standing leg raise left

Airplane

Half moon

(repeat sequence on left)

Dancer's pose (right, left, right, left)

Tree (right, left)

1 breath per pose

(vinyasa through Sun salutation A to Downward facing dog)

Warrior 1

5 breaths per pose

Warrior 2

Triangle

Side facing forward fold with a bind 
Pyramid with a bind

Twisting triangle

(vinyasa to downward facing dog,

repeat on left side)

1 breath per pose

(vinyasa through Sun salutation A to downward facing dog)

High push up, lower to floor

5 breaths per pose

Locust $x 2$

Floor bow $x 2$

(one breath in between poses)

1 breath per pose

Upward facing dog

Downward facing dog

5 breaths per pose

Camel $\times 2$

(vinyasa to downward facing dog)

Bridge $x 1$

Wheel $\times 6$

Supine butterfly

Happy baby

1 breaths per pose

Knees to chest
Rock forward to seat

5 breaths per pose

Boat

(vinyasa to downward facing dog)

10 breaths per pose

Half pigeon right

Double pigeon right

Half pigeon left

Double pigeon left

(vinyasa to downward facing dog)

Frog

Seated single leg extension right

Seated single leg extension left

Seated forward bend

Table top

Fish

Shoulder stand

Plow

Deaf man's pose

Supine twist right

Supine twist left

Seated butterfly

Savasana

Roll to right side

Come to a seat

Hands to heart center, $3 \mathrm{Om}$ 
APPENDIX F

YOGA POSE MODIFICATION TYPE AND FREQUENCY 


\section{Yoga Pose Modifications}

\section{High/Low Push up}

M1-Knees to floor

M2-Lower all the way to floor

\section{Flip Dog}

M1-Reverse table top

M2- 3 legged dog with hip open

\section{Side Plank}

M1-On forearm

M2-Dropped knee

\section{Crescent Twist}

M1-Knee to floor

Extended Side Angle

M1-Elbow to Knee

\section{Crow}

M1-Feet on floor

M2-Squat

Wheel

M1-Head on floor

M2-Bridge

Floor Bow

M1-Locust pose

\section{Camel}

M1- Hands to low back

\section{Happy Baby}

M1-Grab back of legs instead of feet

\section{Frog}

M1-Child's pose 


\section{Participant Modification Types and Frequency}

\begin{tabular}{|c|c|c|}
\hline Name of Pose & Mod 1 & Mod 2 \\
\hline \multicolumn{3}{|l|}{ Airplane right } \\
\hline \multicolumn{3}{|l|}{ Airplane left } \\
\hline \multicolumn{3}{|l|}{ Balancing half moon right } \\
\hline \multicolumn{3}{|l|}{ Balancing half moon left } \\
\hline \multicolumn{3}{|l|}{ Boat } \\
\hline \multicolumn{3}{|l|}{ Bridge } \\
\hline Camel 1 & 2 & \\
\hline Camel 2 & 4 & \\
\hline \multicolumn{3}{|l|}{ Child's pose } \\
\hline \multicolumn{3}{|l|}{ Crescent lunge right } \\
\hline \multicolumn{3}{|l|}{ Crescent lung twist right } \\
\hline \multicolumn{3}{|l|}{ Crescent lunge left } \\
\hline \multicolumn{3}{|l|}{ Crescent lunge twist left } \\
\hline Crow 1 & 4 & \\
\hline Crow 2 & 5 & \\
\hline \multicolumn{3}{|l|}{ Dancer's pose right 1} \\
\hline \multicolumn{3}{|l|}{ Dancer's pose left 1} \\
\hline \multicolumn{3}{|l|}{ Dancer's pose right 2} \\
\hline \multicolumn{3}{|l|}{ Dancer's pose left 2} \\
\hline \multicolumn{3}{|l|}{ Deaf man's pose } \\
\hline \multicolumn{3}{|l|}{ Double pigeon right } \\
\hline \multicolumn{3}{|l|}{ Double pigeon left } \\
\hline \multicolumn{3}{|l|}{ Downward facing dog } \\
\hline \multicolumn{3}{|l|}{ Eagle right 1} \\
\hline \multicolumn{3}{|l|}{ Eagle left 1} \\
\hline \multicolumn{3}{|l|}{ Eagle right 2} \\
\hline \multicolumn{3}{|l|}{ Eagle left 2} \\
\hline Extended side angle right & 14 & \\
\hline \multirow{2}{*}{\multicolumn{3}{|c|}{$\begin{array}{l}\text { Extended side angle left } \\
\text { Fish } \\
\end{array}$}} \\
\hline & & \\
\hline Flip dog right & 1 & \\
\hline Flip dog left & 1 & \\
\hline Floor bow 1 & 2 & \\
\hline Floor bow 2 & 2 & \\
\hline Forward fold fingers to toes & & \\
\hline Forward fold palms to hands & & \\
\hline Frog & & \\
\hline Half pigeon right & & \\
\hline Half pigeon left & & \\
\hline Happy baby & & \\
\hline Locust 1 & & \\
\hline Locust 2 & & \\
\hline
\end{tabular}

\begin{tabular}{|l|c|c|}
\hline Name of Pose & Mod 1 & Mod 2 \\
\hline Plow & & \\
\hline Pyramid with bind right & & \\
\hline Ragdoll & & \\
\hline Savasana & & \\
\hline Seated forward bend & & \\
\hline Seated single leg extension right & & \\
\hline Seated single leg extension left & & \\
\hline Shoulder stand & & \\
\hline $\begin{array}{l}\text { Side facing forward fold with } \\
\text { bind 1 }\end{array}$ & & \\
\hline $\begin{array}{l}\text { Side facing forward fold with } \\
\text { bind 2 }\end{array}$ & & \\
\hline Side plank right & 6 & \\
\hline Side plank left & 6 & \\
\hline Standing leg raise right & & \\
\hline Standing leg raise left & & \\
\hline Sun Salutation A x 5 & & \\
\hline Sun Salutation B x 5 & & \\
\hline Supine butterfly & & \\
\hline Supine twist right & & \\
\hline Supine twist left & & \\
\hline Table top & & \\
\hline Thunderbolt chair & & \\
\hline Thunderbolt chair twist right & & \\
\hline Thunderbolt chair twist left & & \\
\hline Tree right & & \\
\hline Triangle right & & \\
\hline Triangle left & & \\
\hline Twisting triangle right & & \\
\hline Twisting triangle left & & \\
\hline Upward facing dog & & \\
\hline Warrior 1 right & & \\
\hline Warrior 1 left & & \\
\hline Warrior 2 left & & \\
\hline Warrior 2 right & & \\
\hline Wheel 1 & & \\
\hline Wheel 2 & & \\
\hline Wheel 3 & & \\
\hline Wheel 4 & & \\
\hline Wheel 5 & & \\
\hline Wheel 6 & & \\
\hline
\end{tabular}

Refer to Yoga Pose Modification Type document to see the definitions for modification 1 and modification 2.

Figure 5. Participant Modification Types and Frequency 
APPENDIX G

HEART RATE MATCHED PROTOCOL 


\section{EXERCISE SESSION PROCEDURES}

1. Compute target exercise heart rate range each 15 minute period from the heart rate achieved for the Yoga Session:

- Target Exercise Heart Rate for Minutes 1-15 = Yoga Heart $\pm 5 \mathrm{bpm}=$ to bpm

- Target Exercise Heart Rate for Minutes $16-30=$ Yoga Heart \pm 5 bpm $=$ to bpm

- Target Exercise Heart Rate for Minutes 31-45 = Yoga Heart $\pm 5 \mathrm{bpm}=$ to

- Target Exercise Heart Rate for Minutes $46-60=$ Yoga Heart $\pm 5 \mathrm{bpm}=$ to bpm

2. Initiate exercise session using the algorithm shown below. 
FLOW CHART FOR HEART RATE MATCHED WALKING SESSION

PARTICIPANT NUMBER:

DATE OF EXERCISE SESSION:

*Note: THR \pm 5 bpm represents the target heart rate range for this exercise session.

\begin{tabular}{|c|c|c|c|}
\hline \multicolumn{3}{|c|}{ Subject walks for a total of 5 minutes (minutes 1-5). } & Set speed and grade of treadmill to $2.0 \mathrm{mph}$ and $0 \%$ grade. Adjust speed by $0.2 \mathrm{mph}$ every 30 seconds until heart rate is within target range. \\
\hline & & & \\
\hline $\begin{array}{l}\text { If average of minutes } 3-5 \text { is }<\text { THR-10 bpm then } \\
\text { increase speed by } 0.5 \mathrm{mph}\end{array}$ & $\begin{array}{l}\text { If average of minutes } 3-5 \text { is THR- } 6 \mathrm{bpm} \text { to THR- } 10 \mathrm{bpm} \\
\text { then increase workload by increasing grade } 0.2 \mathrm{mph}\end{array}$ & $\begin{array}{l}\text { If average of minutes } 3-5 \text { is within } T H R \pm 5 \mathrm{bpm} \\
\text { then maintain this workload. }\end{array}$ & $\begin{array}{l}\text { If average of minutes } 3-5 \text { is }>\text { THR }+5 \mathrm{bpm} \text { decrease } \\
\text { workload by decreasing grade } 0.2 \mathrm{mph}\end{array}$ \\
\hline & 1 & & (- \\
\hline \multicolumn{4}{|c|}{ Subject walks for 5 minutes at this workload (minutes 6-10). } \\
\hline$\square$ & 1 & \begin{tabular}{l|l} 
\\
\end{tabular} & $\square$ \\
\hline $\begin{array}{l}\text { If average of minutes } 6-10 \text { is }<\text { THR- } 10 \mathrm{bpm} \\
\text { then increase workload by increasing grade } 0.5 \\
\mathrm{mph}\end{array}$ & $\begin{array}{l}\text { If average of minutes } 6-10 \text { is THR- } 6 \mathrm{bpm} \text { to THR-10 bpm } \\
\text { then increase workload by increasing grade } 0.2 \mathrm{mph}\end{array}$ & $\begin{array}{l}\text { If average of minutes } 6-10 \text { is THR } \pm 5 \mathrm{bpm} \text { then } \\
\text { maintain this workload. }\end{array}$ & $\begin{array}{l}\text { If average of minutes } 6-10 \text { is }>T H R+5 \mathrm{bpm} \text { decrease } \\
\text { workload by decreasing grade } 0.2 \mathrm{mph}\end{array}$ \\
\hline \multicolumn{4}{|c|}{$1_{1}$} \\
\hline \multicolumn{4}{|c|}{ Subject walks for 5 minutes at this workload (minutes 11-15). } \\
\hline \cline { n }$_{2}$ & $\cos 2 \cos 20$ & & \\
\hline $\begin{array}{l}\text { If average of minutes } 11-15 \text { is }<\text { THR- } 10 \mathrm{bpm} \\
\text { then increase workload by increasing grade } 0.5 \\
\mathrm{mph}\end{array}$ & $\begin{array}{l}\text { If average of minutes } 11-15 \text { is THR- } 6 \text { bpm to THR- } 10 \\
\text { bpm then increase workload by increasing grade } 0.2 \\
\mathrm{mph}\end{array}$ & $\begin{array}{l}\text { If average of minutes } 11-15 \text { is } T H R \pm 5 \mathrm{bpm} \text { then } \\
\text { maintain this workload. }\end{array}$ & $\begin{array}{l}\text { If average of minutes } 11-15 \text { is }>T H R+5 \mathrm{bpm} \\
\text { decrease workload by decreasing grade } 0.2 \mathrm{mph}\end{array}$ \\
\hline & 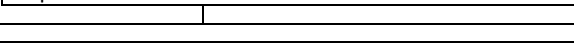 & & \\
\hline \multicolumn{4}{|c|}{ Subject walks for 5 minutes at this workload (minutes 16-20). } \\
\hline & \begin{tabular}{l|l}
-2 \\
\end{tabular} & & \\
\hline $\begin{array}{l}\text { If average of minutes } 16-20 \text { is }<\text { THR- } 10 \mathrm{bpm} \\
\text { then increase workload by increasing grade } 0.5 \\
\mathrm{mph}\end{array}$ & $\begin{array}{l}\text { If average of minutes } 16-20 \text { is THR- } 6 \mathrm{bpm} \text { to THR-10 bpm } \\
\text { then increase workload by increasing grade } 0.2 \mathrm{mph}\end{array}$ & $\begin{array}{l}\text { If average of minutes } 16-20 \text { is } T H R \pm 5 \mathrm{bpm} \text { then } \\
\text { maintain this workload. }\end{array}$ & $\begin{array}{l}\text { If average of minutes } 16-20 \text { is }>\text { THR }+5 \mathrm{bpm} \\
\text { decrease workload by decreasing grade } 0.2 \mathrm{mph}\end{array}$ \\
\hline & 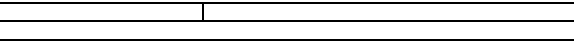 & 1 & (1) \\
\hline \multicolumn{4}{|c|}{ Subject walks for 5 minutes at this workload (minutes 21-25). } \\
\hline$\Upsilon_{2}$ & 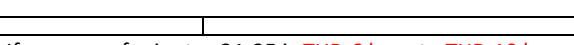 & & \\
\hline $\begin{array}{l}\text { If average of minutes } 21-25 \text { is }<\text { THR- } 10 \mathrm{bpm} \\
\text { then increase workload by increasing grade } 0.5 \\
\mathrm{mph}\end{array}$ & $\begin{array}{l}\text { If average of minutes } 21-25 \text { is THR- } 6 \mathrm{bpm} \text { to THR-10 bpm } \\
\text { then increase workload by increasing grade } 0.2 \mathrm{mph}\end{array}$ & $\begin{array}{l}\text { If average of minutes } 21-25 \text { is } T H R \pm 5 \mathrm{bpm} \text { then } \\
\text { maintain this workload. }\end{array}$ & $\begin{array}{l}\text { If average of minutes } 21-25 \text { is }>\mathrm{THR}+5 \mathrm{bpm} \\
\text { decrease workload by decreasing grade } 0.2 \mathrm{mph}\end{array}$ \\
\hline & suig to & ( & - \\
\hline \multicolumn{4}{|c|}{ Subject walks for 5 minutes at this workload (minutes 26-30). } \\
\hline 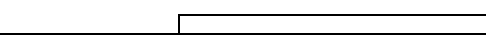 & \begin{tabular}{c|c}
1 \\
\end{tabular} & & \\
\hline $\begin{array}{l}\text { If average of minutes } 26-30 \text { is }<\text { THR- } 10 \mathrm{bpm} \\
\text { then increase workload by increasing grade } 0.5 \\
\mathrm{mph}\end{array}$ & $\begin{array}{l}\text { If average of minutes } 26-30 \text { is THR- } 6 \mathrm{bpm} \text { to THR- } 10 \mathrm{bpm} \\
\text { then increase workload by increasing grade } 0.2 \mathrm{mph}\end{array}$ & $\begin{array}{l}\text { If average of minutes } 26-30 \text { is } T H R \pm 5 \mathrm{bpm} \text { then } \\
\text { maintain this workload. }\end{array}$ & $\begin{array}{l}\text { If average of minutes } 26-30 \text { is }>T H R+5 \mathrm{bpm} \\
\text { decrease workload by decreasing grade } 0.2 \mathrm{mph}\end{array}$ \\
\hline
\end{tabular}




\begin{tabular}{|c|c|c|c|}
\hline $\begin{array}{l}\text { If average of minutes } 31-35 \text { is }<T H R-10 \text { bpm } \\
\text { then increase workload by increasing grade } 0.5 \\
\mathrm{mph}\end{array}$ & $\begin{array}{l}\text { If average of minutes } 31-35 \text { is THR- } 6 \text { bpm to THR-10 bpm } \\
\text { then increase workload by increasing grade } 0.2 \mathrm{mph}\end{array}$ & $\begin{array}{l}\text { If average of minutes } 31-35 \text { is THR } \pm 5 \text { bpm then } \\
\text { maintain this workload. }\end{array}$ & $\begin{array}{l}\text { If average of minutes } 31-35 \text { is }>T H R+5 \mathrm{bpm} \\
\text { decrease workload by decreasing grade } 0.2 \mathrm{mph}\end{array}$ \\
\hline \multicolumn{4}{|c|}{ Subject walks for 5 minutes at this workload (minutes 36-40). } \\
\hline $\begin{array}{l}\text { If average of minutes } 36-40 \text { is }<\text { THR- } 10 \text { bpm } \\
\text { then increase workload by increasing grade } 0.5 \\
\mathrm{mph}\end{array}$ & $\begin{array}{l}\text { If average of minutes } 36-40 \text { is THR- } 6 \mathrm{bpm} \text { to THR- } 10 \mathrm{bpm} \\
\text { then increase workload by increasing grade } 0.2 \mathrm{mph}\end{array}$ & $\begin{array}{l}\text { If average of minutes } 36-40 \text { is THR } \pm 5 \mathrm{bpm} \text { then } \\
\text { maintain this workload. }\end{array}$ & $\begin{array}{l}\text { If average of minutes } 36-40 \text { is }>T H R+5 \mathrm{bpm} \\
\text { decrease workload by decreasing grade } 0.2 \mathrm{mph}\end{array}$ \\
\hline \multicolumn{4}{|c|}{ Subject walks for 5 minutes at this workload (minutes 41-45). } \\
\hline $\begin{array}{l}\text { If average of minutes } 41-45 \text { is }<T H R-10 \text { bpm } \\
\text { then increase workload by increasing grade } 0.5 \\
\mathrm{mph}\end{array}$ & $\begin{array}{l}\text { If average of minutes } 41-45 \text { is THR- } 6 \text { bpm to THR-10 bpm } \\
\text { then increase workload by increasing grade } 0.2 \mathrm{mph}\end{array}$ & $\begin{array}{l} \\
\text { If average of minutes } 41-45 \text { is } T H R \pm 5 \text { bpm then } \\
\text { maintain this workload. }\end{array}$ & $\begin{array}{l}\text { If average of minutes } 41-45 \text { is }>T H R+5 \mathrm{bpm} \\
\text { decrease workload by decreasing grade } 0.2 \mathrm{mph}\end{array}$ \\
\hline \multicolumn{4}{|c|}{ Subject walks for 5 minutes at this workload (minutes 46-50). } \\
\hline $\begin{array}{l}\text { If average of minutes } 46-50 \text { is }<\text { THR- } 10 \mathrm{bpm} \\
\text { then increase workload by increasing grade } 0.5 \\
\mathrm{mph}\end{array}$ & $\begin{array}{l}\text { If average of minutes } 46-50 \text { is THR- } 6 \mathrm{bpm} \text { to THR- } 10 \mathrm{bpm} \\
\text { then increase workload by increasing grade } 0.2 \mathrm{mph}\end{array}$ & $\begin{array}{l}\text { If average of minutes } 46-50 \text { is } T H R \pm 5 \text { bpm then } \\
\text { maintain this workload. }\end{array}$ & $\begin{array}{l}\text { If average of minutes } 46-50 \text { is }>T H R+5 \mathrm{bpm} \\
\text { decrease workload by decreasing grade } 0.2 \mathrm{mph}\end{array}$ \\
\hline \multicolumn{4}{|c|}{ Subject walks for 5 minutes at this workload (minutes 51-55). } \\
\hline $\begin{array}{l}\text { If average of minutes } 51-55 \text { is }<\text { THR- } 10 \text { bpm } \\
\text { then increase workload by increasing grade } 0.5 \\
\mathrm{mph}\end{array}$ & $\begin{array}{l}\text { If average of minutes } 51-55 \text { is THR- } 6 \mathrm{bpm} \text { to THR-10 bpm } \\
\text { then increase workload by increasing grade } 0.2 \mathrm{mph}\end{array}$ & $\begin{array}{l}\text { If average of minutes } 51-55 \text { is } T H R \pm 5 \text { bpm then } \\
\text { maintain this workload. }\end{array}$ & $\begin{array}{l}\text { If average of minutes } 51-55 \text { is }>T H R+5 \mathrm{bpm} \\
\text { decrease workload by decreasing grade } 0.2 \mathrm{mph}\end{array}$ \\
\hline & Subject walks for 5 minutes & orkload (minutes 56-60). & \\
\hline & Reduce speed until treadmill stops, and then have th & the remainder of the 5 minutes recovery period. & \\
\hline
\end{tabular}

Figure 6. Flow Chart for Heart Rate Matched Walking Session 


\section{BIBLIOGRAPHY}

1. Troiano RP, Berringan D, Dodd KW. Physical activity in the United States measured by accelerometer. Med Sci Sports Exerc. 2008;40:181-188.

2. US Department of Health and Human Services. Physical Activity Guidelines Advisory $\begin{array}{lll}\text { Committee } & \text { Report } 2008 .\end{array}$ http://www.health.gov/paguidelines/committeereport.aspx. Accessed January 19, 2009.

3. US Department of Health and Human Services. Physical Activity and Health: A Report of the Surgeon General. Atlanta: GA: US Department of Health and Human Services, Centers for Disease Control and Prevention, National Center for Chronic Disease Prevention and Health Promotion; 1996.

4. Ogden CL, Carroll MD, Kit BK, Flegal KM. Prevalence of childhood and adult obesity in the United States, 2011-2012. JAMA. 2014;311(8):806-814.

5. Jensen MD, Ryan DH, Apovian CM, et al. 2013 AHA/ACC/TOS guideline for the management of overweight and obesity in adults: a report of the American College of Cardiology/American Heart Association Task Force on Practice Guidelines, and The Obesity Society. Circulation. 2013;129(25 (Suppl. 2)):S102-138.

6. National Institutes of Health National Heart Lung and Blood Institute. Clinical Guidelines on the Identification, Evaluation, and Treatment of Overweight and Obesity in Adults - The Evidence Report. Obes. Res. 1998;6(Suppl. 2). 
7. Donnelly JE, Blair SN, Jakicic JM, Manore MM, Rankin JW, Smith BK. ACSM position stand on appropriate intervention strategies for weight loss and prevention of weight regain for adults. Med Sci Sports Exerc. 2009;42(2):459-471.

8. Iyengar BKS. Light on yoga. New York: Schocken Books; 1966.

9. $\quad$ Baptiste B. Journey into power. New York: Simon \& Schuster; 2003.

10. Li AW, Goldsmith CA. The effects of yoga on anxiety and stress. Altern Med Rev. 2012;17(1):21-35.

11. Michalsen A, Grossmon P, Acil A, et al. Rapid stress reduction and anxiolysis among distressed women as a consequence of a three-month intensive yoga program. Med Sci Monit. 2005;11(12):555-561.

12. Galantino ML, Bzdewka TM, Eissler-Russo JL, et al. The impact of modified Hatha yoga on chronic low back pain: a pilot study. Altern Ther Health Med. 2004;10(2):56-59.

13. Ghasemi GA, Golkar A, Marandi SM. Effects of Hata yoga on knee osteoarthritis. Int $J$ Prev Med. 2013;4(Suppl. 1):S133-S138.

14. Sherman KJ, Cherkin DC, Wellman RD. A randomized trial comparing yoga, stretching, and a self-care book for chronic low back pain. Arch Int Med. 2011;171:2019-2026.

15. Uebelacker LA, Epstein-Lubow G, Guadiano BA, Tremont G, Battle CL, Miller IW. Hatha yoga for depression: critical review of the evidence for efficacy, plausible mechanisms of action, and directions for future research. J Psychiatr Pract. 2010;16(2223).

16. Woolery A, Myers H, Sternlieb B, Zelter L. Yoga intervention for young adults with depression. Altern Ther Health Med. 2004;10(2):60-63. 
17. Kawade RC. Yoga improves flexibility. Variorum, Multi-Disciplinary e-Research Journal. 2011;1(III (February)).

18. Tekur P, Singphow C, Nagendra HR, Raghuram N. Effect of a short term program on pain, functional disability, and spinal flexibility in chronic low back pain: a randomized control study. J Altern Complement Med. 2008;14(6):637-644.

19. Khalsa SBS. Treatment of chronic insomnia with yoga: a preliminary study with sleepwake diaries. Appl Psychophysiol Biofeedback. 2004;29(4):269-278.

20. Mustian M, Sproad LK, Janelsins M, et al. Multcenter, randomized controlled trial of yoga for sleep quality among cancer survivors. J Clin Oncol. 2013;10(31):3233-3241.

21. Bharshankar J, Bharshankar R, Deshpande V, Kaore S, Gosavi G. Effect of yoga on cardiovascular system in subjects above 40 years. Indian $J$ Physiol Pharmcol. 2003;41(2):202-206.

22. Hagins M, Moore W, Rundle A. Does practicing hatha yoga satisfy recommendations for intensity of physical activity which improves and maintains health and cardiovascular fitness? BMC Complement Altern Med. 2007;7:40.

23. Carroll J, Bansit A, Otto RM, Wygand JW. The metabolic requirements of Vinyasa Yoga. Med Sci Sports Exerc. 2003;35(5):S155.

24. Garber CE, Blissmer B, Deschenes MR, et al. American College of Sports Medicine Postion Stand. Quantity and quality of exercise for developing and maintaining cardiorespiratory, mucsuloskeletcal, and neuromotor fitness in apparently healthy adults: guidance for prescribing exercise. Med Sci Sports Exerc. 2011;43(7):1334-1359.

25. Wing RR. Physical activity in the treatment of adulthood overweight and obesity: current evidence and research issues. Med Sci Sports Exerc. 1999;31(11(suppl)):S547-S552. 
26. Alexander G, Innes K, Bourguignon C, Bovberg V, Kulbok P, Taylor A. Pattern of yoga practice and physical activity following a yoga intervention for adults with or at risk for type 2 diabetes. J Phys Act Health. 2012;9(1):53-61.

27. Guarracino J, Savino S, Edelstein S. Yoga participation is beneficial to obesity prevention, hypertension control, and positive quality of life. Focus on Obesity and Weight Management. 2006;21(2):108-113.

28. Telles S, Naveen V, Balkrishna A, Kumar S. Short term health impact of a yoga and diet change program on obesity. Med Sci Monit. 2010;16(1):CR 35-40.

29. Telles S, Sharma SK, Yadav A, Singh N, Balkrishna A. A comparative controlled trial comparing the effects of yoga and walking for overweight and obese adults. Med Sci Monit. 2014;20:894-904.

30. Tranchant $\mathrm{T}$, Larocque M, Russel J, Stotland S. Weight loss, stress responses and depression in obese patients: usefulness of an online questionnaire for assessment and management of psychological and behavioural factors. Proc Nutr Soc. 2008;67(OCE):E180.

31. Richardson AS, Arsenault JE, Cates SC, Muth MK. Perceived stress, unhealthy eating behaviors, and severe obesity in low-income women. Nutr J. 2015;14:122.

32. Ross A. The health benefits of yoga and exercise: a review of comparison studies. $J$ Altern Complement Med. 2010;16(1):3-12.

33. West J, Otte C, Geher K, Johnson J. Effects of hatha yoga and African dance on perceived stress, affect, and salivary cortisol. Ann Beh Med. 2004;28:114-118. 
34. Mansur RB, Brietzke E, McIntyre RS. Is there a "metabolic-mood syndrome"? A review of the relationship between obesity and mood disorders. Neurosci Biobehav Rev. 2015;52:89-104.

35. Trief PM, Cibula D, Delahanty LM, Weinstock RS. Depression, stress, and weight loss in individuals with metabolic syndrome in SHINE, a DPP translation study. Obesity. 2014;22(12):2532-2538.

36. Wing RR, Greeno CG. Behavioural and psychosocial aspects of obesity and its treatment. Bailliere Clin Endoc. 1994;8(3):689-703.

37. Nicholls W, Devonport TJ, Blake M. The association between emotions and eating behaviour in an obese population with binge eating disorder. Obes Rev. 2015;doi: 10.1111/obr.12329.

38. Andersen RE, Crespo CJ, Bartlett SJ, Bathon JM, Fontaine KR. Relationship between body weight gain and significant knee, hip, and back pain in older americans. Obesity. 2012;11(10):1159-1162.

39. Masheb RM, Lutes LD, Kim HM, et al. Weight loss outcomes in patients with pain. Obesity. 2015;23:1778-1784.

40. Schaller A, Dejonghe L, Haastert B, Froboese I. Physical activity and health-related quality of life in chronic low back pain patients: a cross-sectional study. BMC Musculoskelet Disord. 2015;19(16):62.

41. Segura-Jiménez V, Borges-Cosic M, Soriano-Maldonado A, et al (in press). Association of sedentary time and physical activity with pain, fatigue, and impact of fibromyalgia: the al-Ándalus study. Scand J Med Sci Sports. 2015. 
42. Patel S, Malhotra A, White DA, Gottlieb DJ, Hu F. Association between reduced sleep and weight gain in women. Am J Epidemiol. 2006;10(164):947-954.

43. Spiegel K, Tasali E, Penev P, Cauter EV. Sleep curtailment in healthy young men is associated with decreased leptin levels, elevated ghrelin levels, and increased hunger and appetite. Ann Intern Med. 2004;141:846-850.

44. Tapper K, Shaw C, Islay J, Hill AJ. Exploratory randomized controlled trial of a mindfulness-based weight loss intervention for women. Appetite. 2009;52:396-404.

45. Mason AE, Epel ES, Kristeller J, et al. Effects of a mindfulness-based intervention on mindful eating, sweets consumption, and fasting glucose levels in obese women: data from the SHINE randomized controlled trial. J Behav Med. 2016;39(2):201-13.

46. Kristeller J, Wolever RQ, Sheets V. Mindfulness-based eating awareness training (MBEAT) for binge eating: a randomized clinical trial. Mindfulness. 2014;5(3):282-297.

47. Segal KR, Gutin B, Presta E, Wang J, Van Itallie TB. Estimation of human body composition by electrical impedance methods: a comparative study. J Appl Physiol. 1985;58(5):1565-1571.

48. Paffenbarger RS, Hyde RT, Wing AL, Hsieh CC. Physical activity, all-cause mortality, and longevity of college alumni. $N$ Engl J Med. 1986;314:605-613.

49. Hill JO, Peters JC, Wyatt HR. Using the Energy Gap to Address Obesity: A Commentary. J Am Diet Assoc. 2009;109(11):1848-1853. 